\title{
Attenuated Spreading in Sanskrit Retroflex Harmony
}

\section{Citation}

Ryan, Kevin. 2017. “Attenuated Spreading in Sanskrit Retroflex Harmony." Linguistic Inquiry 48 (2) (April): 299-340. doi:10.1162/ling_a_00244.

\section{Published Version}

doi:10.1162/LING_a_00244

\section{Permanent link}

http://nrs.harvard.edu/urn-3:HUL.InstRepos:34945788

\section{Terms of Use}

This article was downloaded from Harvard University's DASH repository, and is made available under the terms and conditions applicable to Open Access Policy Articles, as set forth at http:// nrs.harvard.edu/urn-3:HUL.InstRepos:dash.current.terms-of-use\#OAP

\section{Share Your Story}

The Harvard community has made this article openly available.

Please share how this access benefits you. Submit a story.

Accessibility 
Kevin M. Ryan

Preprint (in press in Linguistic Inquiry 48.2, 2017; not identical to published version)

\title{
Attenuated spreading in Sanskrit retroflex harmony*
}

\begin{abstract}
Drawing on a two-million-word corpus of Sanskrit, the article documents and analyzes two previously unrecognized generalizations concerning the morphoprosodic conditioning of retroflex spreading (nati). Both reveal harmony to be attenuated across the left boundaries of roots (i.e., between a prefix and a root or between members of a compound), in the sense that while harmony applies across these boundaries, when it does so, it accesses a proper subset of the targets otherwise accessible. This attenuation is analyzed here through the 'ganging up' of phonotactics and output-output correspondence in serial Harmonic Grammar. The article also simplifies the core analysis of the spreading rule, primarily through recognizing FlAPOUT, an articulatorily grounded constraint.
\end{abstract}

Sanskrit exhibits a consonant harmony process called nati by which retroflexion spreads progressively and at any distance from a retroflex continuant trigger to a coronal nasal target (e.g., 1a-b), assuming that no consonantal coronal intervenes to block it (1c). A trigger can occupy any morphological position, including a prefix (1d).

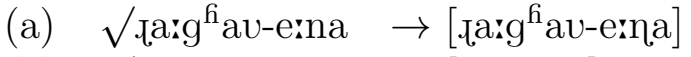
'by the descendant of Raghu'
(b) $\sqrt{ }$ Jug-na-
$\rightarrow$ [utg-na- $]$
'broken'
(c) $\sqrt{ }$ rat ${ }^{\mathrm{h}}$-e:na $\rightarrow\left[\right.$ rat ${ }^{\mathrm{h}}$-e:na $]$
'by the chariot'
(d)
p.a- $\sqrt{ }$ hi-no:-ti
$\rightarrow$ [p.a-hi-no:-ti
'incites'

Nati has drawn the attention of linguists for nearly three thousand years. Among generative phonologists, it has played significant roles in treatments of harmony, (non-)iterativity, feature geometry, autosegmentalism, and prosodic phonology (section 1), and it continues to inform new developments. Recently, for instance, Jardine (2014) identified nati as one of only two known segmental (as opposed to tonal) processes in the world's languages with the potential to be 'unbounded circumambient', that is, sensitive to unbounded contexts on both sides of the target (see section 4). Hansson (2010: 189-91) identifies several respects in which nati is unusual among consonant harmony systems, including the nonoverlap between triggers and target, the coronal blocking of a coronal harmony, the progressive directionality, and the (occasional) phrasal domain. One might add that prefixes rarely initiate harmony crosslinguistically (Baković 2000, Hyman 2002, Krämer 2003, Kenstowicz 2009).

The present article has two goals. First, it simplifies previous analyses of the core facts of nati, primarily through incorporating into the analysis a phonetic property of retroflex stops, namely, 'flapping out' (i.e. releasing in a more anterior position). Sanskrit is argued

\footnotetext{
* Parts of this article were presented at the 12th Old World Conference in Phonology and the Harvard Indo-European Workshop. I gratefully acknowledge the suggestions and criticisms of those audiences, Dieter Gunkel, Joe Pater, Rachel Walker, the reviewers, and the editors.
} 
to be normal typologically in that its retroflex stops flap out, while its retroflex continuants do not. This constraint explains a number of at first glance disparate properties of nati, including its trigger set, its noniterativity, its progressive directionality, and some aspects of blocking (section 2).

Second, drawing on a two-million-word corpus of Vedic and Epic Sanskrit, this article revisits the primary data, identifying and analyzing two previously unrecognized (including by the grammars) morphological conditions on nati. Both independently reveal the left boundaries of roots to attenuate spreading, in the sense that harmony accesses fewer targets after it crosses a boundary. In particular, cross-boundary harmony never affects immediately postplosive targets, whereas stem-internal harmony almost always does so (section 3). Moreover, cross-boundary harmony rarely accesses targets in preretroflex position, whereas stem-internal harmony always does so (section 4).

Both cases are analyzed in Harmonic Grammar (HG) through the 'ganging up' of the relevant independently motivated markedness constraint ( ${ }^{*} \mathrm{~T} n$, or the Obligatory Contour Principle) with an output-output correspondence constraint, $\operatorname{IDENT}_{O O}([$ retro] $)$, which requires derived forms to match their bases' retroflexion. As a brief illustration of this principle, steminternal harmony almost always accesses post-plosive targets (e.g. [ $\sqrt{ }$ fug-na- $]$ 'broken', [ $\sqrt{ }$ t.jpnu-] 'be pleased with'), revealing that a proharmony constraint - say, SHARE-outweighs ${ }^{*} \mathrm{Tn}$ (plus input-output IDENT $I O$ ). Harmony also normally applies across root boundaries

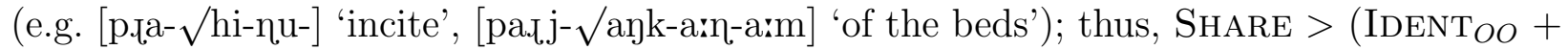
$\left.\operatorname{IDENT}_{I O}\right)$. But when both of these situations arise simultaneously, as when harmony must cross a root boundary to reach a postplosive target, harmony fails (e.g. [p.la- $\sqrt{ } b^{f}$ ag-na-] 'crushed', [p.- $\sqrt{ }$ a:p-nu-] 'attain'). This generalization is captured if the summed weight of $\left({ }^{*} \mathrm{T \eta}+\mathrm{IDENT}_{O O}+\mathrm{IDENT}_{I O}\right)$ exceeds that of SHARE.

This analysis is argued to be superior to other conceivable approaches not involving HG, serialism, or output-output correspondence (section 5). Optimality Theory (OT) approaches relying on morphological indexation or constraint conjunction are criticized in sections 5.15.2. A stratal OT account is addressed in section 5.3. Finally, nonserial HG, while able to capture the gang effects described here, is arguably more pathological than its serial counterpart (section 5.4).

\section{The language and corpus}

The basic facts surrounding nati ([nəti]; English pronunciation ['n $\Lambda$ ti]) have been recounted numerous times since antiquity. Pānini (ca. 500-350 BCE) treats them in a set of 39 rules in the last chapter of the last book of his grammar, the Aștādhyāyī (section 8.4.1-39; see Böhtlingk 1887: 461-72, Vasu 1898: 1651-70). Nati is also discussed in the Prātiśākhyas, ancient treatises on Vedic pronunciation (Wackernagel 1896: 188, Allen 1951: 940).

The term nati, literally 'bending, curvature' (Allen 1953: 66), was not used by Pānini; rather, it appears in the Prātiśākhyas (Rk-Pr. 5.61, Vājasaneyi-Pr. 1.42). It refers to tongue retroflexion as an articulatory process. To refer to the retroflexes as a class, the ancient phoneticians used a different term, mürdhanya 'cerebral', from mürdhán, the relevant passive 
articulator. The term nati sometimes appears in print erroneously with an initial retroflex, but is properly dental-initial, as in the Prātiśākhyas, coming from a zero-grade nominalization $\left(<{ }^{*} n m_{o}-t i\right)$ of the root $\sqrt{ }$ nam 'bend', the same root found in 'namaste' (nam-as=te), literally '[a] bow [to] thee'. It does not, as the spelling * nati would suggest, mean something like 'n-ification'. While nati can in principle refer to any process of retroflexion, it is used here, as elsewhere, to refer only to retroflex harmony affecting nasals.

Notable modern grammatical descriptions include Whitney (1889: 64-6 = section 18995), Wackernagel (1896: 186-95 = section 167-74; with notes by Debrunner 1957: 102-7), Brugmann (1897: 352, 849 = section 401.4, section 973), Macdonell (1910: 38-40 = section 47), Allen (1951: 940-6), and Renou (1952: 55-8 = section 60-5; 1961: 16-8 = section 17-8). In terms of the coverage of the data, however, Wackernagel (1896) is hardly superseded by these or other works (cf. Grammont 1950:251f, Collinge 1965, Langendoen 1968:84, Burrow 1973:97, among others).

Among generative linguists, nati has featured prominently in analyses of consonant harmony, feature geometry, autosegmental spreading, and prosodic phonology, including those by Johnson (1972: 13-61), Vergnaud and Halle (1978), Selkirk (1980: 122-5), Kiparsky (1985: 113), Sagey (1986: 134), Schein and Steriade (1986: 717-9, 720-3), Steriade (1986, 1995), Avery and Rice (1989:192f, 1991), Cho (1991), Shaw (1991), Kaun (1993), Clements and Hume (1995: 289), Flemming (1995a:112f, 1995b), Humbert (1995: 192-205), Ní Chiosáin and Padgett (1997: 35-41), Gafos (1999: 207-14, 220-4), Halle et al. (2000: 423f), Hansson (2001: 223-43, 2010: 179-93), Hamann (2003: 122f, 195f), Rose and Walker (2004: 518f, 2011: 284f), Kaplan (2008: 20f), Graf (2010: 71-6), Jurgec (2011: 20-4), Arsenault (2012: 14450), Cathcart (2012: 79ff), Jardine (2014: 15f), and others. Even in 1951, Allen could already refer to nati as 'only too well-known' (940). Half a century later, Gafos (1999: 177, 209) could identify it as both 'notorious' and 'a prototypical case of long-distance assimilation', though most analyses, including Allen (1951) and Gafos (1999), analyze it as strictly local spreading. These various strains of research are cited as relevant below.

The language names used in this article, while standard, deserve comment, since different authors employ them with different degrees of specificity. First, 'Sanskrit' here refers to all of Old Indic (also known as Old Indo-Aryan). It is not used here to refer only to Classical Sanskrit, as it sometimes is elsewhere. Sanskrit in this broad sense can in turn be divided at the coarsest into two periods, the older 'Vedic' (c. 1500-600 BCE) and the younger 'Classical' (c. 600- BCE), the latter more closely conforming to Pānini's rules (Masica 1993: 50-5). 'Classical' thus construed subsumes the two Sanskrit epics.

When this article cites corpus counts, they derive from the texts enumerated in Figure 1, all downloaded from the Göttingen Register of Electronic Texts in Indian Languages. ${ }^{1}$ The texts, arranged roughly by chronology (the Rg-Veda being the oldest extant Sanskrit text), are labeled according to period and genre. Abbreviations are given in parentheses. For example, ' $10 \mathrm{v} 1 \mathrm{~b} 5 \mathrm{e}$ ' would mean that the form is attested sixteen times total in the corpus: 10 times in the Vedas, 1 time in the Brăhmanas, and 5 times in the epics. The corpus includes over two million words in total, roughly one third Vedic and two thirds Epic.

\footnotetext{
${ }^{1}$ gretil.sub.uni-goettingen.de, accessed May 2014.
} 
Since the corpus is not exhaustive, additional forms from dictionaries, grammars, and other texts are also cited when relevant, though not included in corpus statistics.

\begin{tabular}{|c|c|c|c|}
\hline Period & Genre & Text & Word Count \\
\hline \multirow[t]{9}{*}{ Vedic } & Vedas & Rg-Veda & 164,767 \\
\hline & & Sāma-Veda & 19,019 \\
\hline & & Atharva-Veda & 85,021 \\
\hline & Brāhmaṇas & (Mādhyạ̣dina) Śatapatha & 127,255 \\
\hline & & Pañcaviṃśa & 42,700 \\
\hline & & Gopatha & 31,267 \\
\hline & & (Bāṣkala) Kauṣittaki & 39,060 \\
\hline & Early Upaniṣads $(\mathbf{u})$ & Brhadāraṇyaka & 16,502 \\
\hline & & Chāndogya & 13,968 \\
\hline \multirow[t]{2}{*}{ Epic $(\mathbf{e})$} & & Mahābhārata & $1,258,457$ \\
\hline & & Rāmāyaṇa & 213,773 \\
\hline
\end{tabular}

Total: $2,011,789$

Figure 1: Sources and abbreviations covered in the corpus reports below. Each is given with its period, genre, and orthographic word count.

The consonant and vowel inventories of Sanskrit are shown in Figures 2 and 3, respectively (e.g. Cardona 2003). While this article employs the IPA for citing data (though not for names of texts, technical terms, etc.), the IPA can be easily converted back to the standard romanization using these tables. IPA transcriptions below depart from these tables only in giving the short low vowel as [a], as it is normally transcribed, despite its schwa-like quality. For the handful of vowels for which the Vedic and Classical values differ, the Classical values can always be assumed, as is standard practice. The letter anusvāra $(m)$, usually said to be a kind of placeless but moraic nasal coda (cf. Japanese), is omitted from the figure.

The rhotic, a retroflex continuant and by far the most common trigger of nati, is transcribed here, with its syllabic variants, as [ı], though it may have been (or varied with) tapped or trilled [r]. Whitney (1889: section 24, section 52), for one, identifies it as untrilled, noting, among other things, that ' $[\mathrm{n}] \mathrm{o}$ authority hints at a vibration as belonging to it', as might be expected for a trill, given the general articulatory detail commanded by the ancient phoneticians. Indeed, one ancient prescription refers to excessive contact (atisparśa) as a barbarism (barbaratā) (Allen 1951: 54). Other possible but not strong hints at the smoothness of the rhotic include its productive participation in s-rhotacism (Catford 2001), its frequent metatheses and glide-like alternations in syllabicity, and its status as a reflex of both ${ }^{*} r$ and ${ }^{*} l$ ( $i b i d$. section 53). Furthermore, as section 2.2 elaborates, the fact that the rhotic initiates a domain of progressive retroflex spreading indicates that it does not 'flap out' into a more anterior position on its release. Since retroflex stops and flaps typically flap out, while retroflex fricatives do not, this diagnostic might also support a smooth rhotic, though a tap/trill is not ruled out. ${ }^{2}$

${ }^{2}$ While generally recognized to be retroflex, some ancient phonetic treatises suggest instead an alveolar 


\begin{tabular}{|c|c|c|c|c|c|c|}
\hline & Labial & Dental & Retroflex & Palatal & Velar & Glottal \\
\hline \multirow[t]{4}{*}{ Plosive } & $\begin{array}{ll}p & {[\mathrm{p}]}\end{array}$ & $\begin{array}{ll}t & {[\mathrm{t}]}\end{array}$ & $\begin{array}{ll}t & {[\mathrm{t}]}\end{array}$ & $\begin{array}{ll}c & {[\mathrm{c}]}\end{array}$ & $\begin{array}{ll}k & {[\mathrm{k}]}\end{array}$ & \\
\hline & $p h \quad\left[\mathrm{p}^{\mathrm{h}}\right]$ & th $\quad\left[\mathrm{t}^{\mathrm{h}}\right]$ & the $\quad\left[\mathrm{t}^{\mathrm{h}}\right]$ & $c h \quad\left[\mathrm{c}^{\mathrm{h}}\right]$ & $k h \quad\left[\mathrm{k}^{\mathrm{h}}\right]$ & \\
\hline & $b \quad[\mathrm{~b}]$ & $d \quad[\mathrm{~d}]$ & [d] & $j \quad[f]$ & $g \quad[g]$ & \\
\hline & $b h \quad\left[\mathrm{~b}^{\mathrm{h}}\right]$ & $d h \quad\left[\mathrm{~d}^{\mathrm{h}}\right]$ & $d h \quad\left[\mathrm{~d}^{\mathrm{f}}\right]$ & $j h \quad\left[\mathrm{f}^{\mathrm{h}}\right]$ & $g h \quad\left[g^{h}\right]$ & \\
\hline Fricative & {$[\Phi]^{*}$} & $s \quad[\mathrm{~S}]$ & [S] & $s^{\prime} \quad[6]$ & {$[\mathrm{x}]^{*}$} & $h \quad[h]$ \\
\hline & & & & & & $n$ \\
\hline Nasal & $m \quad[\mathrm{~m}]$ & $n \quad[\mathrm{n}]$ & [n] & {$[\mathrm{n}]$} & {$[y]$} & \\
\hline Lateral & & $l \quad[1]$ & $l^{*} \quad[l] *$ & & & \\
\hline & & & $l h^{*} \quad\left[l^{\mathrm{K}}\right] *$ & & & \\
\hline Rhotic & & & [I] & & & \\
\hline Glide & $v \quad[v]$ & & & $y \quad[\mathrm{j}]$ & & \\
\hline
\end{tabular}

Figure 2: Sanskrit consonant inventory, with standard Indologists' transcription in italics followed by IPA. Asterisked phones are specifically Vedic, $[\phi]$ and $[\mathrm{x}]$ being variant pronunciations of $h$. The chart includes phones usually assumed to be allophonic, viz., $[\mathrm{n}],[\mathrm{y}],[\mathrm{h}],[\phi],[\mathrm{x}],[\mathrm{l}]$, and $\left[\mathrm{l}^{\mathrm{f}}\right]$.

As the caption to Figure 2 implies, dental /n/ vs. retroflex / $/$ / is a phonemic contrast in Sanskrit (cf. e.g. [pa:na] 'drinking' vs. [pa:na] 'stake in a game'). Nevertheless, its functional load is low, the vast majority (over $80 \%$ ) of tokens of [n] being due to nati. ${ }^{3}$

This article uses final hyphens in citing words only when they would be hyphenated in standard romanization. The lack of a hyphen does not imply that the word could stand alone as such. For example, the word nati itself could never occur as nati without an ending (e.g. nominative singular [nati-h]), but is normally cited as nati, not nati- or natih. Internal hyphens, which are often problematic, are supplied freely when convenient, but always when the morphology is relevant to the application of nati. As is also common practice in citing Sanskrit words, pitch accent is marked when convenient (generally when a word is being quoted from a text in which accent is marked), though lack of a marked accent does not imply that the word lacks an accent or that its location is unknown.

place for the rhotic (Allen 1951: 54f). As Allen clarifies, even if it were alveolar phonetically (in some dialects), it is clearly functionally retroflex. See Cathcart (2012) on why an anterior rhotic might still induce retroflexion.

${ }^{3}$ The present corpus includes 122,680 tokens of [n]. Of these, $82.4 \%$ occur in a nati context, though this figure includes occasional false positives in which underlying $/ \mathrm{n} /$ happens to occur in nati context and excludes occasional false negatives in which nati obtains across a word boundary. 


\begin{tabular}{|c|c|c|c|}
\hline & Front & Central & Back \\
\hline High & $i \quad[\mathrm{i}]$ & & $u \quad[\mathrm{u}]$ \\
\hline & $\bar{l} \quad[\mathrm{i}: \mathbf{i}]$ & & $\bar{u} \quad[\mathrm{ur}]$ \\
\hline Mid & $e \quad[\mathrm{e}]\left([\mathrm{ai}]^{*}\right)$ & & $o \quad[\mathrm{O}:]\left([\mathrm{au}]^{*}\right)$ \\
\hline Low & & $a \quad[ə]$ & \\
\hline & & $\bar{a} \quad[\mathrm{a}:]$ & \\
\hline Diphthong & $a i \quad[\mathrm{ai}]\left([\mathrm{ari}]^{*}\right)$ & & $a u \quad[\mathrm{au}]\left([\mathrm{aru}]^{*}\right)$ \\
\hline \multirow[t]{3}{*}{ Syllabic C } & \\
\hline & \multicolumn{3}{|l|}{ 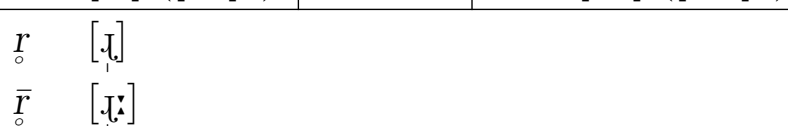 } \\
\hline & \multicolumn{3}{|l|}{$[1]$} \\
\hline
\end{tabular}

Figure 3: Sanskrit vowel and syllabic consonant inventory. As before, asterisked transcriptions are Vedic pronunciations. All items can be considered phonemic.

\section{Triggers, targets, blockers, and the importance of flapping out in their analysis}

\subsection{Preliminary data}

Nati is a progressive (left-to-right) consonant harmony. Its triggers are all and only the non-lateral retroflex continuants, $\left\{\tau_{\mathrm{l}} \mathrm{l}: \mathrm{s}\right\}$ (on the status of $\left\{l l^{\mathrm{h}}\right\}$ as (non)triggers, which has not previously been discussed, see section 2.4). Its lone target is the dental $/ \mathrm{n} /$, which becomes retroflex [n]. Harmony obtains across an arbitrarily long string of segments so long as no blocker intervenes. Blockers (also called opaque segments) comprise the consonantal (i.e. excluding $[\mathrm{j}]$ ) coronals. These basic properties are summarized in (2). The domain is typically the word (though occasionally larger or smaller). For the most part (though see section 3), harmony is blind to morphology. For example, a rhotic in a prefix will target a visible nasal in a root, suffix, infix, or other prefix; a rhotic in a suffix will target subsequent suffixes; and so forth. Syllabic position is also irrelevant. Nati applies only if the target immediately precedes a vowel, glide, or nasal; on this restriction, see section 2.4.

$$
\begin{aligned}
& \text { Directionality: progressive } \\
& \text { Triggers: } \quad \text { †. } \\
& \text { Target: } \quad n \\
& \text { Outcome: } \quad \text {, } \\
& \text { Blockers: consonantal coronals, that is, }
\end{aligned}
$$

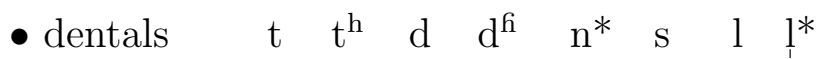

$$
\begin{aligned}
& \text { - retroflexes } \mathrm{t} \quad \mathrm{t}^{\mathrm{h}} \mathrm{d}, \mathrm{d}^{\mathrm{h}} \mathrm{n}^{*} \mathrm{~s}^{*} \quad \mathrm{l} \mathrm{l}^{\mathrm{h}} \mathrm{I}^{*} \quad \mathrm{I}^{*} \quad \mathrm{f}^{*} \\
& \text { - palatals c } \mathrm{c}^{\mathrm{h}} \mathrm{f} \quad \mathrm{f}^{\mathrm{h} *} \mathrm{n}^{*} 6 \\
& \text { *Unattested or ambiguous as blockers; see text. }
\end{aligned}
$$


As an illustration, consider the instrumental singular suffix /-erna/ (see also e.g. Hansson 2010:179-85 for a different presentation of the basic data). When attached to a stem lacking a trigger, it surfaces as such, as in (3). (The 'vs. 0' addendum to a corpus citation makes it explicit that no counterexample is found in the corpus; in general, however, patterns suggested by example sets are entirely regular unless otherwise noted.) When the stem contains an (unblocked) trigger, the suffix undergoes nati, as shown in (4).
(a) ká:m-e:na 'by desire'
(v10 b3 e37 vs. 0)
(b) pad-éna 'by step'
(v2 b5 vs. 0)
(c) ba:n-e:na 'by arrow'
(e66 vs. 0$)$
(d) mu:d. -e:na 'by the stupid (one)' (e6 vs. 0)
(e) gaf-e:na 'by elephant'
(v10 b3 e37 vs. 0)
(f) jo:g-e:na 'by means'
(e37 vs. 0)
(g) j-éna 'by which/whom'
(v212 b62 u6 e769 vs. 0)
(h) guf-e:na 'by cave'
(e6 vs. 0)
(a) na.-e:ña
'by man'
(e18 vs. 0$)$
(b) manusj-eña
'by human'
(e20 vs. 0)
(c) d díáţ-e:ña
'by dharma'
(b1 u1 e295 vs. 0)
(d) c.ng-e:na
'by horn'
(e4 vs. 0)

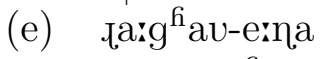
'by the Rāghava'
(e28 vs. 0$)$
(f) vişamb ${ }^{\text {fi }}$-eña 'by span'
(e3 vs. 0)
(g) t.jjayg-e:na
'by tripartite'
(e1 vs. 0)
(h) puspaug
'by the heap of flowers' (e1 vs. 0)

As mentioned, harmony is blocked by an intervening coronal. This subsumes the dental, retroflex, and palatal series, with the one exception of the palatal glide $/ \mathrm{j} /$, which is always transparent (as in (4-b, g)). Some blockers are exemplified in (5). Items (5) (e-f) also reinforce that retroflex stops do not serve as triggers (see also (3) (c-d)).
(a) ját $\mathrm{t}^{\mathrm{h}}$-e:na 'by chariot'
(b) pa:ssat-e:na
'by the antelope'
(v63 b11 e111 vs. 0)
(c) hifdaj-e:na 'by heart'
(e18 vs. 0$)$
(d) visal-ena
'by the wicked man'
(v2 b6 u3 e30 vs. 0)
(e) vi.ja:t-e:na
'by Virāta'a'
(e1 vs. 0)
(f) gafud-e:na
'by Garuda'
(e14 vs. 0)
(g) ґa:jj-enna
'by royal'
(e5 vs. 0)
(h) ma:jicc-enna 'by the Mārīca'
(e34 vs. 0)
(e4 vs. 0)

Certain coronals, while possible to analyze as blockers, cannot be illustrated in blocking position. First, $/ \mathrm{l} /$ and $/ \mathrm{f}^{\mathrm{f}} /$, while expected to block, are rare and unattested in diagnostic positions in the corpus. Lacking evidence to the contrary, they are assumed to behave like $/ \mathrm{l} /$ and $/ \mathrm{J} /$. The situation is similar for the palatal nasal, which is only attested adjacent to a palatal stop in the corpus and therefore cannot be isolated as a blocker, though it is presumed to be one. Second, as previously observed (Gafos 1999:213, Arsenault 2012:147), the triggers - all coronal - are ambiguous in their status as blockers, since they could be 
either transparent or blocking with retriggering; see (6). The status of these segments as blockers is therefore free to follow from theory-internal considerations.
(a) kșir.-érna 'by milk' (v1 e8 vs. 0)
(b) cáfiir.-e:na 'by the body' (v1 b1 e33 vs. 0)

Finally, the dental nasal cannot occur in blocking position because it itself undergoes harmony, becoming [n]. In such cases (as with underlying $/ \eta /$, which is not a trigger), harmony does not spread beyond the undergoing /n/ to the next $/ \mathrm{n} /$; see (7). Thus, coronal nasals can also be considered blockers.
(a) pła:n-é:na
'by breath'
(v15 b57 u17 e11 vs. 0)
(b) kșan-eina
'by an instant'
(b1 e108 vs. 0)
(c) hí.janj-e:na
'by gold'
(v2 b3 e4 vs. 0)
(d) p.̧a:jạírj-e:na
'by introductory'
(b11 vs. 0)

\subsection{Core analysis}

The facts introduced to this point are analyzed in this section; additional complications will be considered in sections 3 and 4 . A key and often overlooked component of their explanation, it is maintained here, concerns 'flapping out' (Ladefoged 1964), a property of retroflex stops (including nasals) by which the tongue tip moves forward during the closure phase of the segment, releasing into a more anterior position (ibid., Bhat 1973:47, Dave 1977, Simonsen et al. 2000, Dart 1991, Shalev et al. 1993, Butcher 1995, Krull et al. 1995, Steriade 1995:5f, Spajić et al. 1996, Dart and Nihalani 1999, Flemming 2003, Hamann 2003, Boersma and Hamann 2005, Arsenault 2012). As such, retroflex stops are contour segments, so to speak, and could be narrowly transcribed as such, e.g. narrow [ tt $]$ for broad [t] (Boersma and Hamann 2005:21ff). The narrower transcription does not imply that the release of a retroflex stop is homophonous with that of a dental stop; it indicates only that the release enters an anterior (e.g. alveolar) configuration (Steriade 1995: 6).

The acoustic consequence of flapping out is that the F3 depression associated with retroflexion is realized more prominently in the $\mathrm{VC}$ than $\mathrm{CV}$ transition. Flapping out has been documented palatographically for retroflex stops of Australia, Scandinavia, and South Asia (including daughters of Sanskrit such as Hindi and Gujarati; op. cit.), and is further corroborated by their phonological behavior, particularly their better cueing by lefthand context (e.g. Steriade 1995, Hamann 2003). But flapping out does not apply to all retroflexes. As Boersma and Hamann (2005: 18) clarify, while it is a typical, perhaps even universal, property of retroflex stops, it appears not to characterize retroflex fricatives (see also Bhat 1973: 47 and Flemming 2003: 346 in tentative agreement with this caveat). The lack of flapping out of retroflex fricatives is also supported by their phonology, particularly their frequent interactions with following vowels (Boersma and Hamann 2005: 18f).

It is therefore assumed on both typological and internal grounds that the Sanskrit retroflex stops flap out, while the retroflex fricative does not. Internal grounds include the behavior of stops vs. fricatives in nati, as explained presently, as well as their licensing requirements: Retroflexion is contrastive for stops only in post-vocalic position (with marginal 
exception due to onomatopoeia and dialect borrowing), while the retroflex fricative is more broadly distributed (e.g. [șát] 'six' vs. [sát] 'being'). Thus, [ș] is narrowly [ș], not [Șs]. Note that retroflex continuants also possess stronger internal cues to their anteriority, which could also support their broader licensing.

While the typology is less clear for retroflex rhotics, internal grounds support treating Sanskrit [I] like [s] in terms of flapping out. Aside from its comparably broad licensing (e.g. it occurs word-initially, where it remains retroflex, as confirmed by nati), the fact that both [.]] and $[\mathrm{s}$ ] serve as triggers for progressive retroflexion is itself prima facie evidence of their lack of flapping out, given that the consensus holds nati to be a spreading harmony (e.g. Flemming 1995b, Gafos 1999, Ní Chiosáin and Padgett 2001, Rose and Walker 2004, Hansson 2010, Jurgec 2011). That the mechanism of nati is strictly local spreading (i.e. gestural extension) as opposed to agreement across non-undergoing interveners is supported by the existence of blockers, progressive directionality, disjoint triggers and target, and the (occasional) phrasal domain (op. cit., especially Hansson 2010: 189ff). In order to initiate a progressive domain of retroflex spreading, the retroflex continuants cannot flap out. This asymmetry between stops and continuants is summarized in (8). ${ }^{4}$ In what follows, retroflex stops will continue to be given their broad transcriptions, with the understanding that they flap out.

\begin{tabular}{l|llll} 
& onset $(\mathrm{V}$-to-C) & offset $(\mathrm{C}-$ to-V) & broad & narrow \\
\hline retroflex continuants & posterior & posterior & {$[\mathrm{s}]$} & {$[\mathrm{s}]$} \\
retroflex stops & posterior & anterior & {$[\mathrm{n}]$} & {$[\mathrm{nn}]$} \\
dentals & anterior & anterior & {$[\mathrm{n}]$} & {$[\mathrm{n}]$}
\end{tabular}

The constraint enforcing flapping out in stops is here called FLAPOUT. Loosely speaking, this constraint requires every retroflex coronal stop to have an anterior offset. Coronal is specified because non-coronal stops can link to [retroflex] on this analysis (as when retroflexion spreads through them), and non-coronal retroflexes such as [k] are not accompanied by flapping out. In terms of autosegmental spans, the constraint, as in (9), demands that every retroflex coronal stop coincide with the right edge of its span of retroflexion.

(9) FlapOut: Penalize every retroflex coronal stop that is non-final in its span of retroflexion.

One other caveat is that only released retroflex stops flap out. A cluster such as /nt./, for

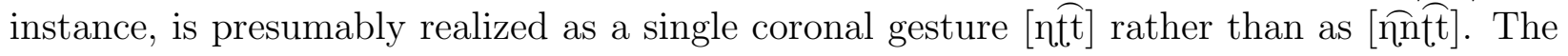
latter, which contains a dental stop between two retroflex stops, can be ruled out by other constraints (much as, say, [kqk] would be). GEN may also produce candidates in which such clusters share their [retroflex] feature. In such candidates, the no-line-crossing convention and (possibly Gen-encoded) NoGAP, which forbids discontinuous spans (Kiparsky 1981, Archangeli and Pulleyblank 1994, Walker 2014), together ensure that the first part does not flap out.

Next, a constraint is required to motivate the harmony, whose mechanism appears to be strictly local spreading as opposed to long-distance agreement with intervening non-

\footnotetext{
${ }^{4}$ As mentioned, non-triggering by retroflex laterals is treated in section 2.4.
} 
undergoers (op. cit.). Several constraint-based approaches to spreading can be found in the literature, including Align, Spread, Specify, *A-Span, Agree, and $\forall$-Harmony; see Wilson (2003) and McCarthy (2009b, 2011) for overviews and pathologies of these proposals. Here, Share(retro) is employed, following McCarthy's (ibid.) schema, as in (10).

ShARE([retro]) (abbreviated SHARE): For every pair of adjacent segments, assign a penalty if they are not both linked to the same token of [retroflex].

Given the autosegmental setting, the spreading feature is often taken to be privative, as with [retroflex] here, agreeing with recent analyses of Sanskrit (e.g. Ní Chiosáin and Padgett 2001) and other languages (e.g. McCarthy 2009b, 2011, Walker 2014). This assumption is not crucial here; if binary [anterior] or [TTCO] (Tongue Tip Constriction Orientation; Gafos 1999) were instead employed, the constraint definitions could be recalibrated. Also following McCarthy (ibid.), SHARE([retro]) is taken to be violated by a pair of adjacent segments in which neither segment is linked to [retroflex].

A competing faithfulness constraint, IDENT([retro]) (11), penalizes changing a segment's anteriority. In the tableaux, this constraint is taken to be violated by $/ \mathrm{n} / \rightarrow[\mathrm{n}]$ even though the latter, assuming it flaps out, retains an anterior release. At any rate, since IDENT is not an active constraint here, this detail of formulation is irrelevant. For a fuller analysis of retroflex licensing and contrast in Sanskrit, see section 2.3.

IDENT([retro]) (abbreviated IDENT): Penalize a segment whose anteriority differs from its input correspondent.

The constraint-based framework employed here, for reasons to be clarified in section 5, is serial Harmonic Grammar (SHG; Pater 2012, Mullin 2011, Kimper 2011), which is the same as Harmonic Serialism (McCarthy 2009b, 2011) except set in Harmonic Grammar (HG; Legendre et al. 1990, Smolensky and Legendre 2006, Pater 2009b, Potts et al. 2010) rather than Optimality Theory (OT; Prince and Smolensky 1993/2004, McCarthy and Prince 1993). SHG is like classical OT and HG in that each language comes with a fixed ranking or weighting of constraints. Unlike classical OT and HG, however, only one operation (e.g. addition or deletion of an association line) is permitted per GEN/EVAL cycle, and the output of each evaluation is recycled as an input to a new evaluation until no more changes are optimizing, at which point the derivation converges. Furthermore, since it is serial HG rather than OT, constraints have real-valued nonnegative weights and the violation score of a candidate is the weighted sum of its violations, which are taken to be nonpositive integers. The candidate with the greatest harmony wins. On harmony in HS, as well as more general background on the theory, see McCarthy $(2009 b, 2011)$ and references therein.

Tableau series (12) illustrates the derivation of [fana] 'delight' from (possible input) /rana/. Parentheses indicate spans of retroflexion, i.e., strings in which every segment is linked to the same token of [retroflex]. Retroflexion is redundantly marked on every segment within the span, using an underdot if the IPA lacks a symbol. Since only one operation is permitted per step, the span grows one segment at a time until it reaches target $/ \mathrm{n} /$, at which point it cannot spread any further without violating higher-weighted FLAPOUT. Reducing or deleting the span is never optimizing. In Step 1, candidate (c), which removes 
the retroflex span altogether by anteriorizing the rhotic, violates SHARE three times, one for each pair of adjacent segments, following McCarthy's definition and use of that constraint. When the most faithful candidate wins, as in Step 3, the derivation converges. As is also standard in HS, input-output correspondence constraints such as IDENT are evaluated with respect to the input to the current step, not the original input.

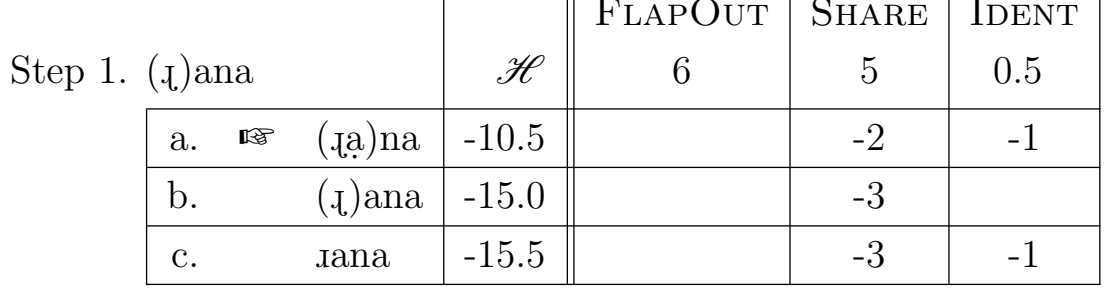

Step 2. (๘а̣)na

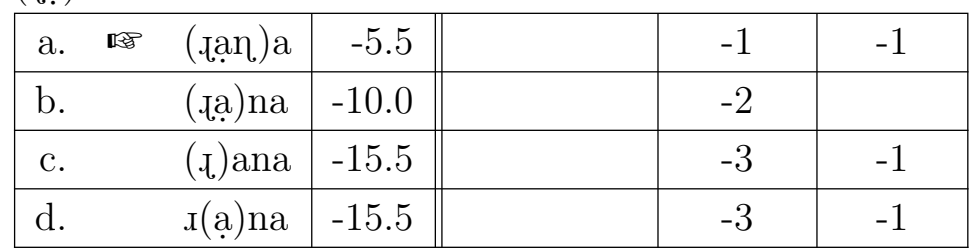

Step 3. ( (ạ) $)$ a

\begin{tabular}{|c|c|c|c|c|}
\hline a. (tạ)a & -5.0 & & -1 & \\
\hline (tạạa) & -6.5 & -1 & & -1 \\
\hline (ла)na & -10.5 & & -2 & -1 \\
\hline
\end{tabular}

The simple weighting of FLAPOUT $>$ SHARE, while not yet the full story, already captures several core features of nati. First, it captures the stop/continuant asymmetry in triggering without specifying it in the harmony apparatus, as reinforced by (13) with [mu:d ${ }^{\mathrm{f}}$-e:na] 'by the fool'. Because retroflex stops flap out (not only in Sanskrit, but perhaps universally), they cannot trigger. As (13) also illustrates, this analysis predicts regressive retroflexion insofar as no blocker interferes (blocking is treated below). No harm comes from this prediction, for two reasons. First, if it were incorrect, one could add a constraint preventing leftward spreading such as InITIAL(feat) (McCarthy 2004, 2009b: 9). But the prediction is not incorrect, at least not on language-internal grounds. Sanskrit orthography distinguishes retroflexion only in coronals. It follows that retroflexion in non-coronals is effectively hidden structure (granting also the impossibility of instrumental study) and free to follow from analytical and typological considerations (Allen 1951: 940ff, Steriade 1995: 51). 
Step 1. $\operatorname{mu}\left(\mathrm{d}^{\mathrm{h}}\right)$-e:na

\begin{tabular}{|c|c|c|c|c|c|}
\hline a. & $\mathrm{m}\left(u \underline{s} \mathrm{~d}^{\mathrm{h}}\right) \mathrm{e}$ na & -20.5 & & -4 & -1 \\
\hline $\mathrm{b}$. & $\operatorname{mu}\left(\mathrm{d}^{\mathrm{h}}\right) \mathrm{e}$ na & -25.0 & & -5 & \\
\hline c. & mu:d f erna $^{2}$ & -25.5 & & -5 & -1 \\
\hline d. & mu:(d d $\left.^{\mathrm{f}} \mathrm{s}\right) \mathrm{na}$ & -26.5 & -1 & -4 & -1 \\
\hline
\end{tabular}

Step 2. m(ụ:di $)$ e:na

\begin{tabular}{|c|c|c|c|c|}
\hline a. $\quad\left(m u ̛: d^{\mathrm{f}}\right)$ e:na & -15.5 & & -3 & -1 \\
\hline $\mathrm{m}\left(\mathrm{urd} \mathrm{d}^{\mathrm{f}} \mathrm{e}\right) \mathrm{na}$ & -21.5 & -1 & -3 & -1 \\
\hline
\end{tabular}

Step 3. (mụ:d $\left.{ }^{\mathrm{h}}\right)$ e:na

\begin{tabular}{|c|c|c|c|c|c|}
\hline a. & $\left(m u ̣: d^{f}\right)$ e:na & -15.0 & & -3 & \\
\hline b. & $\left(\mathrm{mu}_{\mathrm{d}} \mathrm{f} e \mathrm{e}\right) \mathrm{na}$ & -16.5 & -1 & -2 & -1 \\
\hline
\end{tabular}

Second, the analysis predicts the directionality of nati without specifying it in the harmony apparatus. Consider /va:na.a/ 'monkey' in (14). Retroflexion spreads onto the vowels surrounding $/ \mathrm{f} /$, but cannot affect the preceding $/ \mathrm{n} /$, given that $[\eta]$ continued by retroflexion would violate FlAPOUT. Thus, the system embodies the prediction that retroflex spreading harmony targeting stops could only possibly be progressive, as in Sanskrit. Regressive retroflex spreading harmony is attested, as in Kinyarwanda (Walker and Mpiranya 2005, Walker et al. 2008), but its targets are continuants, not stops, consistent with this proposal. This proposal also does not make any predictions about retroflex harmony by correspondence as opposed to spreading (see Arsenault 2012). When multiple orders of operations are tied, only one path is illustrated.

Step 1. va:na(^)a

\begin{tabular}{|c|c|c|c|c|}
\hline a. $\quad$ E & va:na(tạ) & -20.5 & -4 & -1 \\
\hline b. $\quad$ r & vain(ä)a & -20.5 & -4 & -1 \\
\hline c. & vaina(‡)a & -25.0 & -5 & \\
\hline
\end{tabular}

Step 2. va:na(tạ)

\begin{tabular}{|ll|l||l|l|l|}
\hline a. & va:n(ạ.ạ) & -15.5 & & -3 & -1 \\
\hline b. & va:na(tạ) & -20.0 & & -4 & \\
\hline
\end{tabular}

Step 3. va:n(ạ.ạ)

\begin{tabular}{|ll|l||l|l|l|}
\hline a. & va:n(a.ta) & -15.0 & & -3 & \\
\hline b. & va:(nạ.ta) & -16.5 & -1 & -2 & -1 \\
\hline
\end{tabular}

Third, as (15) illustrates (for [ksan-erna] 'by the instant'), the analysis captures the fact that harmony terminates when it reaches a target, rather than continuing on to yet 
another target. In other words, the non-iterativity of harmony is derived from an independent property of the language rather than implemented as an ad hoc parameter or constraint. ${ }^{5}$

\begin{tabular}{|c|c|c|c|c|c|}
\hline \multicolumn{2}{|c|}{ Step 1. k(s)an-erna } & $\mathscr{H}$ & $\begin{array}{c}\text { FLAPOUT } \\
6\end{array}$ & $\begin{array}{c}\text { SHARE } \\
5\end{array}$ & $\begin{array}{c}\text { IDENT } \\
0.5\end{array}$ \\
\hline a. & (ks)ane:na & -25.5 & & -5 & -1 \\
\hline b. $\quad$ o & 哦 $\mathrm{k}($ sạ)ne:na & -25.5 & & -5 & -1 \\
\hline c. & k(s)ane:na & -30.0 & & -6 & \\
\hline
\end{tabular}

Steps 2 and 3 omitted.

Step 4. (kșạ) e:na

\begin{tabular}{|ll|l||l|l|l|}
\hline a. & (kșạ) $)$ e:na & -15.0 & & -3 & \\
\hline b. & (kșạẹ:)na & -16.5 & -1 & -2 & -1 \\
\hline
\end{tabular}

Fourth, harmony is asymmetric in the sense that an anterior continuant does not cause an unblocked retroflex nasal to become anterior (e.g. /sa-gana/ $\rightarrow$ [sa-gana], *[sa-gana] 'along with troops'). This follows from the statement of SHARE, which favors the spreading of retroflexion, but not of anteriority. While the present ranking predicts *[sagana] for this input, the prevention of segments such as /s/ from undergoing harmony is treated in (18). The point here is that anterior continuants are not triggers like retroflex ones.

Fifth, and finally, FLAPOUT covers blocking by retroflex stops (e.g. [vi.ja:t-e:na] 'by Virāța'). Retroflex continuants (e.g. [kși:_-e:na] 'by milk') are also handled appropriately, since the retroflex span is free to spread to $/ \mathrm{n} /$ regardless of the multiplicity of triggers. This leaves only blocking by palatals (except $/ \mathrm{j} /$ ) and dentals. The former can be motivated biokinematically (and hence potentially by GEN), in that a palatal articulation is incompatible (in Sanskrit, if not universally) with tongue tip retroflexion (Gafos 1999:213f, 223f; cf. Hamann 2003, Flemming 2003, Boersma and Hamann 2005). As Gafos (1999: 214) also emphasizes, this articulatory incompatability naturally fails to extend to the palatal vocoid, which involves less arching of the tongue body.

At this point, then, FLAPOUT $>$ SHARE remains incomplete concerning the core data only in that (a) it fails to restrict the targets to $/ \mathrm{n} /$ as opposed to the other anteriors, viz. / $\mathrm{t}^{\mathrm{h}} \mathrm{d} \mathrm{d}^{\mathrm{f}} \mathrm{s} \mathrm{l} \mathrm{l} /$, and (b), relatedly, it fails to capture blocking by anteriors, which are thus far predicted to undergo en route to a target just like non-coronals. For example, the

\footnotetext{
${ }^{5} \mathrm{~A}$ common refrain of rule-based analyses of nati purports to derive its non-iterativity from the fact that a retroflex nasal, the outcome, does not otherwise serve as a trigger, without relating it to any phonetic property (cf. e.g. Johnson 1972, Howard 1973, Anderson 1974, Ringen 1976, Kiparsky 1985). On the present analysis, it is no coincidence that the retroflex nasal neither triggers nor propagates, as both are motivated by FlaPOUt. But the present analysis does not relate the (non)iterativity of a harmonic process to whether or not its trigger(s) and target(s) overlap. It predicts a harmony to be possible in which a segment undergoes and propagates the harmony without triggering it. Indeed, if nati is analyzed as strictly local spreading, then this prediction is borne out even by nati: A segment such as $[\mathrm{k}]$ undergoes and propagates without being a trigger. As a reviewer notes, other cases of non-triggers propagating harmony can be found in Baiyina Orochen (Kaun 2004) and Seto (Kiparsky and Pajusalu 2003).
} 
correct output for / tas-e:na/ is [tas-e:na] 'by flavor', in which /s/ both blocks and fails to undergo retroflexion. But the ranking so far generates *[taş-enna], in which /s/ is both transparent to and undergoes retroflexion.

Following Ní Chiosáin and Padgett (1997: 36; also Ohala and Ohala 1993, Padgett 1995, Gafos 1999, Steriade 1995, 2009), place is generally less faithful for nasals than for other consonants, particularly obstruents. For one, nasals are more likely to undergo assimilation, all else being equal. Moreover, diachronically, a contrast between dental and retroflex is less robust for nasals than for plosives, as suggested by the daughters of Sanskrit that lost the $/ \mathrm{n} \sim \mathrm{n} /$ contrast while preserving phonemic retroflexion in the plosives (e.g. Bengali, Nepali, Hindi dialects; Masica 1993). A solution, then, is to rank ShAre below a faithfulness constraint that prevents retroflexion from spreading onto oral coronals, e.g. IDENT ${ }_{\text {OrCor }}$ in (16). This general strategy of FAITH[specific] $\gg$ HARMONY $\gg$ FAITH[general] is not new here but employed by all prior constraint-based analyses of nati (see below) to implement the asymmetry between $/ \mathrm{n} /$ and other dentals. IDENT $\left[\begin{array}{l}+ \text { cor } \\ - \text { nas }\end{array}\right]$ ([retro]) (abbreviated IDENT $_{\text {OrCor }}$ ): Penalize an oral coronal whose anteriority differs from its input correspondent.

In essence, while this approach assumes that [retroflex] can link to any segment (except perhaps the palatals), its interaction with coronals, especially oral coronals, is afforded special faithfulness due to its greater perceptibility on them. Tongue tip orientation during noncoronals is less tightly regulated. Gafos (1999: 222) employs Faith(Tongue Tip Constriction Orientation, Obstruent) to this end, but this constraint fails to account for blocking by /l/ and for the transparency of non-coronal obstruents. The analysis of Ní Chiosáin and Padgett (1997: 36) is dispersion/contrast-based, evaluating paradigms as candidates (cf. Flemming 1995a). The approach here is more classical, and predicts blocking to be independent of the contrastive status of retroflexion in coronals. In Sanskrit, after all, all coronals block, but retroflexion is contrastive for only a subset of them. In particular, there is no anteriority contrast in the laterals in any period, but laterals block in all periods (as do the palatals, for which retroflexion is moot). While one could still maintain that laterals block because retroflexion is contrastive for some coronals in Sanskrit, or because retroflexion is a possible contrast for laterals typologically, invoking contrast at all is unnecessary. The greater perceptibility of retroflexion differences in coronals, especially oral coronals, can be projected onto faithfulness constraints (cf. Steriade 2009). While this explanation still invokes dispersion in some sense, it does not require evaluating paradigms as candidates.

Derivation (17) illustrates both blocking of harmony by an oral coronal and failure of the same oral coronal to undergo harmony. Derivation (18) shows that anticipatory harmony to a coronal continuant is also properly ruled out. 
$(17)$

Step 1. („.)as-e:na

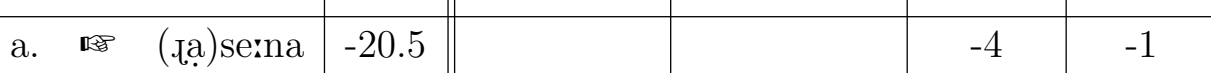

Step 2. (๘ạ)se:na

\begin{tabular}{|c|c|c|c|c|c|}
\hline a. & (גạ)se:na & -20.0 & & -4 & \\
\hline b. & (גaş)e:na & -21.5 & -1 & -3 & -1 \\
\hline
\end{tabular}

Step 1. sa-ga(n)a

\begin{tabular}{|lc|c|c|c|c|c|}
\hline a. & $\operatorname{sag}(a ̣$ ) $)$ a & -20.5 & & & -4 & -1 \\
\hline b. & saga(nạ) & -26.5 & -1 & & -4 & -1 \\
\hline
\end{tabular}

Steps 2 and 3 omitted.

Step 4. s(ạạn)a

\begin{tabular}{|ll|l||l|l|l|l|}
\hline a. & $\mathrm{s}($ ạgạ) $) \mathrm{a}$ & -10.0 & & & -2 & \\
\hline b. & (sagạ $) \mathrm{a}$ & -11.5 & & -1 & -1 & -1 \\
\hline
\end{tabular}

To summarize thus far, the ranking for basic nati, including its trigger and target sets, directionality, non-iterativity, retroflex-anterior asymmetry, and transparent vs. blocking segments, is depicted as a Hasse diagram in (19).

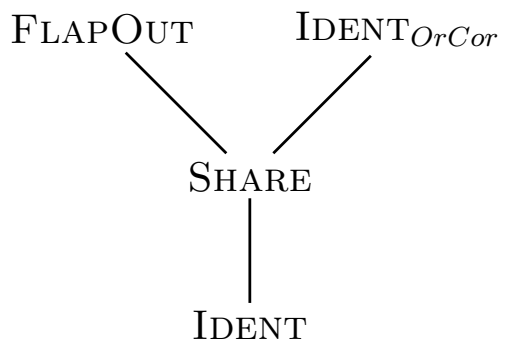

This analysis improves upon previous constraint-based analyses of nati (full OT analyses being offered in Ní Chiosáin and Padgett 1997, 2001 and Gafos 1999; cf. also sketches in Steriade 1995 and Jurgec 2011). First, the proposed pro-harmony constraint is the simplest, merely stating the feature that spreads. The constraint says nothing about the set of triggers, targets, or directionality; all of these properties fall out from interaction with other relatively simple and independently motivated constraints. Compare the pro-harmony constraints in (20)-(23), all of which include one or more features of the triggers and/or target (viz. continuancy and/or coronality), as well as directionality.

(20) TiP Position: 'A nasal apical maintains the same tip position, raised or lowered, as a preceding continuant apical' (Steriade 1995: 51)

(21) Align-R([retroflex], C): 'Align any [retroflex] feature contained in a [+continuant] segment $\mathrm{S}_{m}$ to a consonant $\mathrm{S}_{n}$, where $n>m$ ' (Ní Chiosáin and Padgett 1997: 36) 
HARMONY $($ TTCO $=[$ retroflex $]$, trigger $=[+$ continuant $])$ [in which TTCO refers to Tongue Tip Constriction Orientation and HARMONY is defined essentially as Align-R] (Gafos 1999: 218-23)

ALIGN-R(p-phrase, [-anterior], [+coronal]) (Jurgec 2011: 23)

In the present analysis, the interaction of SHARE and FLAPOUT captures several at first glance disparate properties of nati, including the restriction of triggers to continuants, the progressive directionality (given that the target is a stop), the blocking by retroflex stops, and the non-iterativity of spreading, in the sense that harmony cannot spread through the first eligible target to any following target.

The celebrated non-iterativity of nati (see e.g. Kiparsky 1985:113, Gafos 1999:213, Kaplan 2008:21, Hansson 2010:190) is here an artifact of the target being a stop. In other constraintbased analyses, non-iterativity is stipulated or left unanalyzed (see also footnote 5 on a common rule-based approach). It is stipulated through a dedicated, rankable constraint in Jurgec (2011: 23) and through alignment directly to the target (as opposed to a domain edge) in Ní Chiosáin and Padgett (1997: 36). As explained by Hansson (2010: 186-8), the analysis of Gafos (1999) fails to account for non-iterativity, and alignment-to-target analyses fail to properly handle blocking, at least given the vague formulation of target selection in (21). The analysis here not only covers non-iterativity, but requires it of spreading-driven retroflex harmonies targeting stops. A hypothetical version of Sanskrit with otherwise the same phonetics but iterative nati, or nati feeding another progressive retroflexion, could not exist. At the same time, if the target of retroflexion is a continuant, non-termination and feeding are predicted. Indeed, this prediction is borne out by Sanskrit: Consider ruki, another rule of progressive retroflexion, by which a rhotic, velar, or non-low vowel causes immediately following /s/ to become retroflex (Selkirk 1980, Beguš 2012). Ruki, as predicted, invariably feeds nati, as in / v.s-ana/ $\rightarrow$ [v.s-ana] 'sprinkling', in which the rhotic first triggers retroflexion in the sibilant, which in turn triggers retroflexion in the nasal (recall that [s] would otherwise block nati). This is possible because the target of ruki retroflexion is a continuant, unlike the target of nati retroflexion.

While this section has treated the basic properties of nati, including its triggers, targets, blockers, directionality, and non-iterativity, all of which are known in the phonological literature, some additional complications are documented and analyzed in section 3-4.

\subsection{Addendum concerning contrast}

Retroflexion is contrastive only among coronals in Sanskrit. On the present approach, noncoronals can also bear the feature in Sanskrit, but only non-contrastively, to accommodate harmony or assimilation. In this respect, Sanskrit differs from a language such as Badaga, in which retroflexion is contrastive on vowels (Emeneau 1939 et seq.). A richness-of-the-base input such as /a/ in Sanskrit must therefore neutralize to [a] and also fail to trigger nati.

As an illustration, consider the richness-of-the-base inputs /(^)a-na/ and /p(a)-na/ for

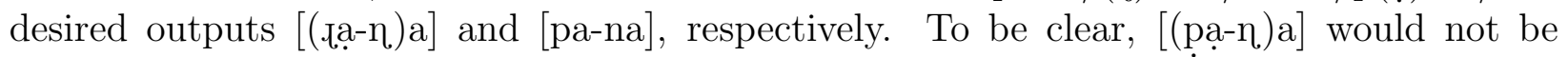
illformed per se, but failure to suppress nati in such cases would erroneously permit the 
existence of coronal-free morphemes that trigger nati, such as a prefix /pa-/, perhaps written pa, but triggering nati on a following root. No such morpheme exists. ${ }^{6}$

Assuming that retroflex non-coronals (including vowels) are marked, ${ }^{*}$ RETRO-NC penalizes them ("NC" for non-coronal, possibly split up into multiple constraints). *RETRO-NC $>\operatorname{IDENT}([$ retro] $])$ causes the neutralization of /a/ and /a/ to [a], as in (24). Candidate (d), in which /ạ/ triggers nati, loses because ${ }^{*} \mathrm{RETRO}_{\mathrm{NC}}$ and $\operatorname{IDENT}_{\text {Cor }}([$ retro]) ("a coronal must retain its input specification for retroflexion") collectively outweigh SHARE. Implicit in this analysis is a p-map or *MAP hierarchy of faithfulness constraints (Steriade 2009, Zuraw 2007, 2013, McCarthy 2009a): $\operatorname{IDENT}_{\text {OrCor }}([$ retro $])>\operatorname{IDENT}_{\text {Cor }}([$ retro $])>\operatorname{IDENT}([$ retro $])$, expressing the fact that changes in retroflexion are most perceptible on oral coronals, followed by nasal coronals and then non-coronals (see section 2.2). Convergence steps and "([retro])" are omitted from tableaux in this section to save space.

\begin{tabular}{|c|c|c|c|c|c|c|c|c|}
\hline \multicolumn{3}{|c|}{ Step 1. p(a)-na } & $\mathscr{H}$ & $\begin{array}{c}\text { IDENT }_{\text {OrCor }} \\
6\end{array}$ & $\begin{array}{c}\text { SHARE } \\
5\end{array}$ & $\begin{array}{c}{ }^{*} \text { Retro-NC } \\
3\end{array}$ & $\begin{array}{c}\operatorname{IDENT}_{\text {Cor }} \\
3\end{array}$ & $\begin{array}{l}\text { IDENT } \\
0.5\end{array}$ \\
\hline & a. & pa-na & -15.5 & & $\begin{array}{l}-3 \\
\end{array}$ & & & -1 \\
\hline $\mathrm{b}$ & b. & (pạ)-na & -16.5 & & -2 & -2 & & -1 \\
\hline & c. & $\mathrm{p}(\mathrm{a})-n a$ & -18.0 & & -3 & -1 & & \\
\hline d & d. & $p(a-\eta) a$ & -16.5 & & -2 & -1 & -1 & -1 \\
\hline
\end{tabular}

Meanwhile, in the context of harmony, spreading across vowels and other non-coronals remains optimal because SHARE outweighs * RETRO-NC and IDENT combined, as in (25).

Step 1. (ォ) a-na

\begin{tabular}{|c|c|c|c|c|c|c|c|}
\hline a. & (๘a)-na & -13.5 & & -2 & -1 & & -1 \\
\hline b. & (.)a-na & -15.0 & & -3 & & & \\
\hline c. & ла-na & -24.5 & -1 & -3 & & -1 & -1 \\
\hline
\end{tabular}

Step 2. (๘ạ)-na

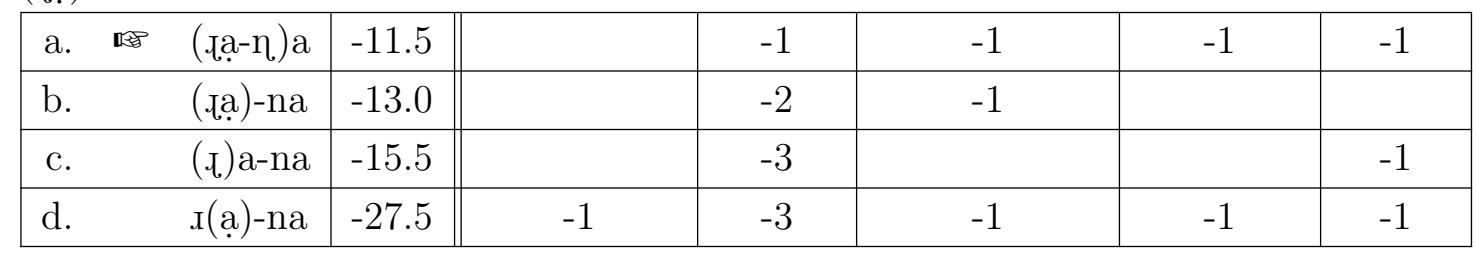

Furthermore, as (26) illustrates, underlying /n/ is properly preserved as such.

\footnotetext{
${ }^{6} \mathrm{I}$ am grateful to an anonymous reviewer for raising this issue and for sketching a solution along the lines of the one pursued here.
} 


\begin{tabular}{|c|c|c|c|c|c|c|}
\hline Step 1. a(n)a & $\mathscr{H}$ & $\begin{array}{c}\text { IDENT }_{\text {OrCor }} \\
6\end{array}$ & $\begin{array}{c}\text { SHARE } \\
5\end{array}$ & $\begin{array}{c}{ }^{*} \text { RETRO-NC } \\
3\end{array}$ & $\begin{array}{c}\text { IDENT }_{C o r} \\
3\end{array}$ & $\begin{array}{c}\text { IDENT } \\
0.5\end{array}$ \\
\hline a. $\quad(a ̣) a$ & -8.5 & & -1 & -1 & & -1 \\
\hline b. $\quad a(\eta) a$ & -10.0 & & -2 & & & \\
\hline ana & -13.5 & & -2 & & -1 & -1 \\
\hline
\end{tabular}

A final technicality concerns the possibility of multi-segment spans of retroflexion preexisting in the input. For example, what if the prefix were not merely $/ \mathrm{p}(\mathrm{a}) /$, as in (24), but /(pa)/? The analysis as it stands predicts that /(pa)/ should trigger nati, as in (27). In other words, a prefix like /(pa)/ is indistinguishable from one like /(ta)/. This treatment is incorrect if it is assumed that a coronal-free morpheme cannot trigger nati.

\begin{tabular}{|c|c|c|c|c|c|c|c|c|}
\hline \multicolumn{3}{|c|}{ Step 1. (pa)-na } & $\mathscr{H}$ & $\begin{array}{c}\text { IDENT OrCor } \\
6\end{array}$ & $\begin{array}{l}\text { SHARE } \\
5\end{array}$ & 3 & $\begin{array}{c}\text { IDENT } \mathrm{T}_{\text {Cor }} \\
3\end{array}$ & $\begin{array}{c}1 D E N 1 \\
0.5\end{array}$ \\
\hline & a. & $($ pạ-n)a & -14.5 & & -1 & -2 & -1 & -1 \\
\hline & $\mathrm{b}$. & (pạ)-na & -16.0 & & -2 & -2 & & \\
\hline & c. & (p)a-na & -18.5 & & -3 & -1 & & -1 \\
\hline & d. & $\mathrm{p}(\mathrm{a})-\mathrm{na}$ & -18.5 & & -3 & -1 & & -1 \\
\hline
\end{tabular}

At least two antidotes are available. First, multi-segment span structure could be absent from lexical representations (as tentatively entertained by McCarthy 2004: 5), which might either lack span structure altogether (much as inputs are often assumed to lack prosodic structure; cf. McCarthy 2008: 303) or limit it to single segments. In either case, a prefix with the underlying form /(pa)/ could not exist. Second, assuming headed spans (McCarthy 2004 et seq.), a constraint could penalize a span of retroflexion with a non-coronal (or nonoral-coronal) head (e.g. * DePENDENT-HeAD in Mullin 2011).

Although ${ }^{*}$ RETRO-NC and IDENT Cor were not made explicit in the tableaux in the previous section (section 2.2), their inclusion in those derivations with the present weights does not alter any of the outcomes shown there.

\subsection{Addenda concerning the basic rule}

Two details concerning the basic rule are yet to be addressed. First, the triggers for nati

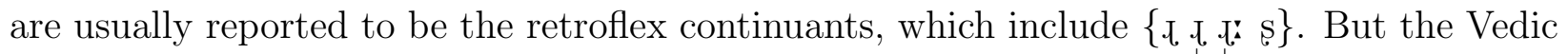
inventory, as Figure 2 suggests, also includes laterals $[\mathrm{l}]$ and $\left[\mathrm{l}^{\mathrm{h}}\right]$, presumably also retroflex continuants. They appear exclusively as allophones of $/ \mathrm{d} /$ and $/ \mathrm{d}^{\mathrm{f}} /$, respectively, in intervocalic position in certain Vedic texts. Judging by 45 diagnostic tokens in the present corpus, retroflex laterals never trigger nati.

Possible causes for this failure include the following. First, it could be synchronic opacity, with lateralization counterfeeding nati. Second, it could be that the apparent opacity is not synchronic but a historical artifact. Under this scenario, at the time of composition, the 
stops would have been pronounced as stops. At some later point in the transmission of the text, lateralization would occur, but without retriggering nati, either because nati had lost productivity, or because the nasals' anteriority was orthoepically fixed. Finally, it is possible that the class of triggers was synchronically not the retroflex continuants, but the central retroflex continuants, potentially with phonetic motivation. Given the laterals' shallow origin in stops, for instance, perhaps they continued to flap out in articulation, in which case they could not trigger. In any case, given the rarity of these allophones and the irrelevance of this issue to the remainder of this article, these questions are left open.

Second, nati is usually reported to apply only if the target immediately precedes a vowel, glide, or nasal, i.e., a non-liquid sonorant. As Schein and Steriade (1986: 720-2) motivate (also Hansson 2010: 183), failure before a liquid, fricative, or word boundary follows from general phonotactics independent of nati, such as word-final neutralization. Only nonapplication before a plosive (e.g. /ca.-a-n-ti/ $\rightarrow$ [ca.-a-n-ti] 'wander (3pl)') requires further comment, as retroflex nasal-plosive clusters are otherwise permitted (e.g. $/ \mathrm{p}^{\mathrm{h}}$ an-ta/ $\rightarrow$ $\left[\mathrm{p}^{\mathrm{h}}\right.$ an-ta] 'spring (pass. part.)'). On the present approach, the step at which the intermediate form [c(a.ja)nti] would yield [c(ạạ)ti] needs to be precluded. This can be accomplished with an appropriate version of CODACOND (McCarthy 2008) penalizing heterorganic nasalplosive clusters. If CODACOND is given a weight of, say, five, the derivation converges at [c(a.a)nti], as desired: The collective violation of CODACOND, IDENT weighs the benefit of spreading to $/ \mathrm{n} / . / \mathrm{p}^{\mathrm{h}}$ an-ta/ $\rightarrow\left[\mathrm{p}^{\mathrm{h}}\right.$ an-ta] is also handled appropriately with this addition. Retraction, as in $\left[\left(\mathrm{p}^{\mathrm{h}} \mathrm{a}\right) \mathrm{n}\right.$-ta], would cost two more violations of SHARE

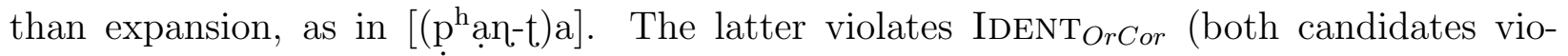
late IDENT $_{C o r}$, IDENT, and CODACOND equally), but not enough to outweigh its benefit from Share. As discussed in section 2.2, homorganic nasal-stop clusters, being single stop gestures, do not violate FLAPOUT.

\section{Boundary attenuation I: post-plosive targets}

One aspect of nati often omitted from generative discussions is that while velars and labials are normally transparent, as illustrated in (4) above, they often block when immediately preceding the target nasal. For example, consider the verb stem [p.- $\sqrt{ }$ a:p- $]$ 'attain' (from preverb [p.a] + root $\sqrt{ }$ a:p). Nati applies without exception whenever the target nasal is post-vocalic, as in (28) and numerous similar examples. But when the nasal immediately follows the final [p] of the stem, as in (29), nati always fails. This failure is not, moreover, a function of the $[\mathrm{nu}] /[\mathrm{no:}]$ suffix (class five present stem formative), as (30) illustrates using the same preverb and suffix but vowel-final root.
(a) p.- $\sqrt{ }$ a:p-ana 'attaining'
(b1 e5 vs. 0)
(b) p.- $\sqrt{ }$ a:p-anirja
'to be attained' (e2 vs. 0)
(a) p.- $\sqrt{ }$ a:p-no:-ti 'attains $(3 \mathrm{~s})$ '
(b) p.- $\sqrt{ }$ a:p-nu-ja:h
'should attain (2s optative)'
(v1 b21 u1 e183 vs. 0)
(u1 e14 vs. 0) 

(a) p.ta- $\sqrt{ }$ hi-no:-ti 'incites $(3 \mathrm{~s})$ '
(b2 e1 vs. 0)
(b) p.ta- $\sqrt{ }$ hi-nu-ja:h 'should incite (2s optative)' (e1 vs. 0)

The post-plosive blocking of nati in (29) no doubt reflects a more general phonotactic of Sanskrit. While $/ \mathrm{n} /$ and $/ \mathrm{n} /$ generally contrast (section 1 ), the contrast is virtually confined to tautomorphemic post-vocalic (occasionally post-sonorant) position (Steriade 1995). Retroflex nasals can be found in post-plosive position, but only due to assimilation. Putting aside nati contexts, if the plosive is coronal, the following coronal nasal must agree in place (e.g. [aátna] 'gift', [atna:_áa] (proper name), [jafná] 'sacrifice'); otherwise, the coronal nasal must be dental (e.g. [suápna] 'sleep', [agní] 'fire'). No isolated lexemes like *[suapna] or *[agni] are found. Thus, Tn appears to be more marked than Tn.

The analysis from section 2.2 can be easily amended by adding a highly ranked constraint forbidding post-plosive retroflexes, e.g. ${ }^{*} \mathrm{~T} \eta$ in (31). While this constraint could likely be generalized further, e.g. to palatal and velar (but not labial) nasals, these details of formulation are unimportant here. Retroflex plosive-nasal clusters (e.g. [atna:.á]) can be motivated by assimilatory constraints dominating ${ }^{*} \mathrm{~T} \eta$, not shown. If $* \mathrm{~T} \eta+$ IDENT $_{C o r}+$ IDENT $>$ SHARE, as in (32), post-plosive nati is suppressed.

*Tr: Penalize a retroflex nasal immediately following a plosive.

(weights to be revised)

\begin{tabular}{|c|c|c|c|c|c|c|}
\hline $\begin{array}{l}\text { Steps } 1-3 \text { omitted. } \\
\text { Step 4. (p.๘ } \sqrt{ } \text { ạp)no:ti }\end{array}$ & $\mathscr{H}$ & $\begin{array}{c}{ }^{*} \mathrm{~T} \eta \\
6\end{array}$ & $\begin{array}{c}\text { SHARE } \\
5\end{array}$ & $\begin{array}{c}* \text { RETRO-NC } \\
3\end{array}$ & $\begin{array}{c}\text { IDENT }_{\text {Cor }} \\
3\end{array}$ & $\begin{array}{c}\text { IDENT } \\
0.5\end{array}$ \\
\hline a. (p. $\sqrt{ }$ ạ:p)no:ti & -29.0 & & -4 & -3 & & \\
\hline (p.l $\sqrt{ }$ a:pn)orti & -33.5 & -1 & -3 & -3 & -1 & -1 \\
\hline
\end{tabular}

Weighting (32) is incorrect, however, since nati does regularly target a post-plosive nasal target in some forms. The data in (33) cover all such forms in the corpus (see section 1), sorted by descending frequency. Irrelevant affixation and compounding is now factored out in the entries, such that only the relevant root and affix, if any, are shown. For example, (d) [té:knas] 'inheritance' includes counts for [té:knas] in various case forms as well as pre-

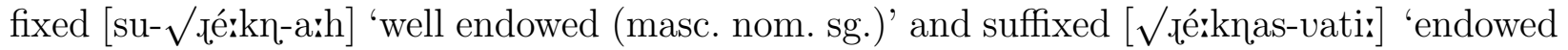
(fem. nom. sg.)'. The 'vs. 0' annotation indicates that the lexeme never occurs in the corpus as *[ré:knas], regardless of genre, period, or morphological context.
(a) $\sqrt{ } g+b^{\mathrm{f}}-\eta \mathrm{V}-$
'grasp (pres. stem)'
(v33 b15 vs. 0)
(b) $\sqrt{ }$ uug-náa
'break (pass. part.)'
(v2 e40 vs. 0)
(c) $\sqrt{ }$ v.jk-náa
'cut off (pass. part.)'
(v4 b7 u7 e2 vs. 0)
(d) $\sqrt{ }$ té:knas
'inheritance'
(v14 vs. 0)
(e) $\sqrt{ }$ t.tp- $n V-$
'be satisfied (pres. stem)'
(v7 vs. v1; AV 20.136.5)
(f) $\sqrt{ }$ tissk-na
'sharp (cf. $\sqrt{ }$ tikkș-na, id.)'
(e5 vs. 0$)$
(g) $\sqrt{ }$ p.tg-na
'unite (pass. part.)'
(v1 vs. 0)
(h) $\sqrt{ }$ đ̣k-na
'wound (pass. part.)'
(b1 vs. 0) 
By contrast, all of the forms in the corpus in which an otherwise eligible post-plosive $/ \mathrm{n} /$ fails to undergo nati are given in (34). ${ }^{7}$ When the trigger is not explicitly shown, as in (c), assume that the ' $\mathrm{X}$-' portion contains a visible trigger. For example, (c) $(\sqrt{ }) \mathrm{X}-\sqrt{ } g^{\mathrm{h}}$ na

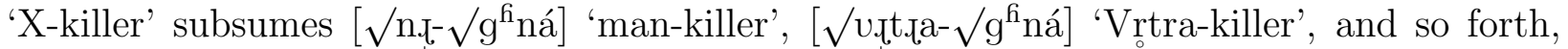
generalizing over irrelevant affixation and compounding as before. Similarly, when 'preverb-' is indicated in the gloss, all applicable trigger-containing preverbs (e.g. [p.a-]) are included.
(a) p.- $\sqrt{ }$ a:p-nV-
'attain (pres. stem)'
(v2 b62 u4 e510 vs. 0)
(b) $(\sqrt{ }) \mathrm{X}-\sqrt{ }$ agni
'X-fire/Agni'
(c) $(\sqrt{ }) X-\sqrt{ } g^{\mathrm{h}}$ na
'X-killer'
(v161 b195 u2 e104 vs. 0)
(d) $\mathrm{X}-\sqrt{ } \mathrm{b}^{\mathrm{h}} \mathrm{ag}-\mathrm{na}$
'preverb-break (pass. part.)'
(v27 b38 e379 vs. 0)
(e) $\mathrm{d}(\mathrm{a}) \mathrm{u}(\mathrm{h})-\sqrt{ }$ șápn-ja
'bad sleep'
(b1 e90 vs. 0)
(f) $X-\sqrt{ } g^{h} n a-$
'preverb-kill (3pl forms)'
(v35 b1 e12 vs. 0)
(g) $\sqrt{ }$ há.ji- $\sqrt{ }$ knika
'bay-colored'
(v5 b14 vs. 0)
(h) pá.jj- $\sqrt{ }$ ak-na
'turned around'
(v2 vs. 0)
(i) ni.- $\sqrt{ }$ vig-na
'unshaken'
(b2 vs. 0)
'fix (pres. stem.)'
(e1 vs. 0)
(j) vi- $\sqrt{ }$ skab - na
'springing (gen. sg.)'
(v1 vs. 0)
(k) $\sqrt{ }$ kșe:p-nó:h
'be satisfied (pres. stem)'
(v1 vs. 0)
(l) $\sqrt{ }$ t.p. nV-
(v1 vs. v7; see (33))

The difference between (33), in which nati applies to post-plosive targets, and (34), in which it does not, is that in all of the cases in (33), no initial root boundary intervenes between trigger and target, whereas in almost all of the cases in (34) (with a handful of exceptions to be addressed below), an initial root boundary intervenes. This root boundary criterion separates tokens into the two categories with almost perfect accuracy (100\% hits and no misses for the first set; $>99 \%$ hits and $<1 \%$ misses for the second). Furthermore, it holds across genres and periods. On its lack of recognition in the previous literature, see the end of this section.

To be sure, some of the nati failures in (34) could be attributed to compounds failing to undergo nati by virtue of being compounds. In Classical Sanskrit, after all, nati often fails to apply across compound boundaries. In Vedic, however, in which nati usually applies across compound boudaries, it never does so when the target is post-plosive. Consider, for example, two derivatives of the root $\sqrt{ }$ han 'kill', namely, /g ${ }^{\mathrm{h}}$ ná/ 'killer' and / hána/ 'killing', in compound-final position. When the first member of the compound contains a trigger, / hána/ undergoes nati, while / $g^{\mathrm{h}}$ ná/ does not, as in (35).

Cross-compound nati:
(a) $\sqrt{ }$ v.t.ta- $\sqrt{ }$ hána
'Vrtra-killing'
(v16 b2 e7 vs. 0)
(b) $\sqrt{ }$ vis.ra- $\sqrt{ }$ hán
'hero-killing'
(b1 e3 vs. 0)

But not to a post-plosive target:

\footnotetext{
${ }^{7}$ [b.jag ${ }^{\mathrm{h}}$ na-] is also found in the corpus (twice in the Sāma-Veda) but omitted from this list since it is a misreading of the Devanāgarī for [b..ad ${ }^{\mathrm{h}} \mathrm{na-}$ ' 'pale', in which /n/ is not eligible for nati.
} 

(a) V v.jt.ja- $\sqrt{ } g^{\mathrm{h}}$ ná
'Vrrtra-killer'
(v6 b5 vs. 0)
(b) $\sqrt{ }$ vi: ‘a- $\sqrt{ } g^{\mathrm{h}}$ ná
'hero-killer'
(v3 e23 vs. 0)

In any case, compounds are not the whole story. Even preverbs that otherwise normally trigger nati in their stems never affect a post-plosive target. This was already demonstrated in (28) through (30); some additional examples involving / pła-/ are given in (37) and (38). Other trigger-containing prefixes (e.g. [pafi-], [duss-]) behave the same.

$$
\begin{aligned}
& \text { /p.a-/ triggers nati in its base: } \\
& \text { (a) p.-a:- } \sqrt{ } \text { hi-no:-t 'incited }(3 \mathrm{~s}){ }^{\prime} \quad \text { (e82 vs. 0) } \\
& \text { (b) p.a- } \sqrt{ } \text { mi:n-a:-ti 'frustrates }(3 \mathrm{~s}) \text { ' (b5 vs. 0) } \\
& \text { (c) p.ta- } \sqrt{\text { jai-na }} \quad \text { 'setting out' (v5 b1 e21 vs. 0) }
\end{aligned}
$$

But not if its target immediately follows a plosive:
(a) p.- $\sqrt{ }$ a:p-no:-ti 'attains (3s)' (v1 b21 u1 e183 vs. 0)
(b) $\left(a b^{\mathrm{h}} \mathrm{i}-\right)$ p.ja- $\sqrt{ } g^{\mathrm{h}} \mathrm{n}$-an-ti
(c) p.a- $\sqrt{ } b^{h} a g-n a$
'kill (3pl)'
(v2 b2 vs. 0)
'broken'
(b1 e72 vs. 0)

To summarize thus far, first, non-coronal plosives are normally transparent to nati, as established in section 2.1 and reinforced here. Coronals, for their part, always block. A non-coronal plosive also blocks iff (a) it immediately precedes the target and (b) the trigger and target straddle a root boundary. The latter configuration is found both when the trigger occupies a prefix and when the trigger occupies a preceding member of a compound.

Schematically, the new generalization can be summarized as in (39), where $\sqrt{ }$ notates the left edge of a root. As the organization of (39) implies, nati failure in (c) can be analyzed by the 'ganging up' (e.g. Jäger and Rosenbach 2006, Kenstowicz 2009, Pater 2009b: 1008ff) of the two markedness constraints implied by (a) and (b) against SHARE. In other words, while neither a violation of (a) alone nor (b) alone is enough to prevent nati, when both (a) and (b) are violated, nati fails in just this 'worst-of-the-worst' case scenario.

(a) Harmony is marked across $\sqrt{ }$.

(b) Retroflexion is marked immediately following a plosive.

(c) Nati applies in spite of (a) and (b), except when both apply simultaneously.

Formally, ganging up can be analyzed using weighted constraints, as in HG (section 2.2). This situation obtains when the weights of two weaker constraints sum to a value greater than that of the stronger constraint (i.e. $w_{1}<w_{3} ; w_{2}<w_{3} ; w_{1}+w_{2}>w_{3}$ ). In the present case, the stronger constraint is SHARE, and one of the two weaker constraints is ${ }^{*} \mathrm{~T} \eta$. The other must penalize cross- $\sqrt{ }$ harmony. The approach adopted here to do so (see section 5 regarding other possibilities) is output-output correspondence (Benua 1995, 1997, Kenstowicz 1996, Ussishkin 1999, Steriade 2000, McCarthy 2005, Zuraw 2013, inter alios), in particular, IDENT $O O$ ([retro]) in (40). The base of correspondence of a prefixed form is its unprefixed counterpart (as with Italian in Kenstowicz 1996). ${ }^{8}$ Members of compounds also stand in correspondence with their uncompounded bases. For example, $[\sqrt{ } /$ fi-no:-ti $]$ is the

${ }^{8}$ Any definition of base selection compatible with this state of affairs is sufficient here. For example, the 


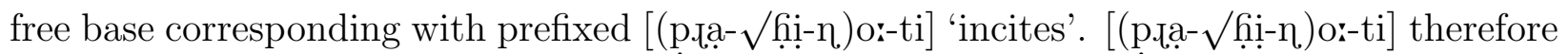
incurs three violations of IDENTOO, one for each segment that undergoes retroflexion.

$\operatorname{IDENT}_{O O}([$ retro] $)$ (abbreviated IDENTOO): Assign a penalty for every segment that differs in anteriority from its correspondent in the base.

Derivation (41) shows a prefix triggering nati when ${ }^{*} \mathrm{~T} \eta$ is not at stake. Because SHARE outweighs IDENT $O O$ (plus the other IDENT constraints), harmonizing across $\sqrt{ }$ is optimal. The convergence step, in which harmony stops at [n] due to FlapOut (section 2.2), is omitted.

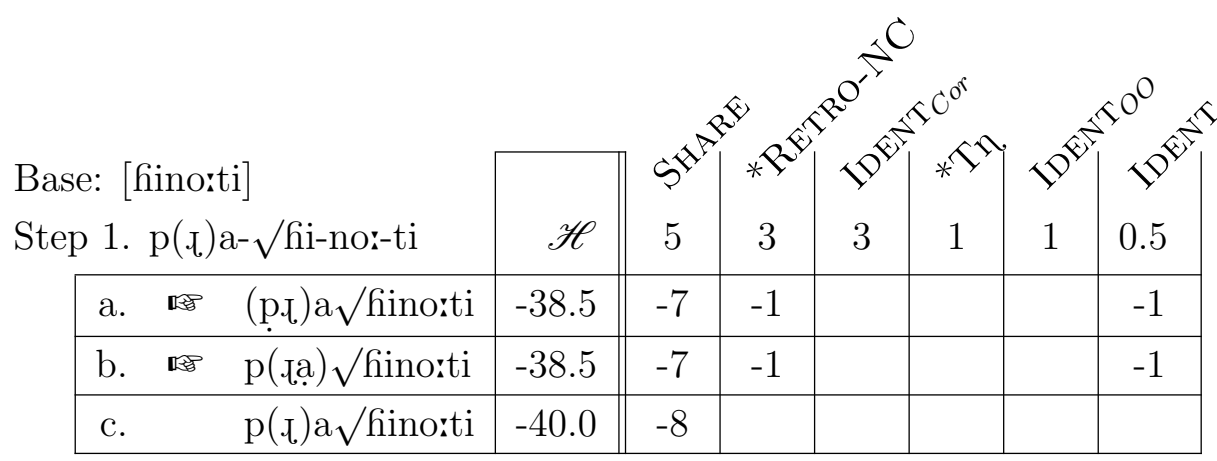

Step 2 omitted.

Step 3. (pдa) $\sqrt{ }$ hino:ti

\begin{tabular}{|lr|l||l|l|l|l|l|l|}
\hline a. & $($ p. \\
\hline b. $\sqrt{ } \sqrt{ }$ h) ino:ti & -35.5 & -5 & -3 & & & -1 & -1 \\
\hline
\end{tabular}

Step 4 omitted.

Step 5. (pıạ $\sqrt{ }$ Gị)no:ti

\begin{tabular}{|c|c|c|c|c|c|c|}
\hline a. (p.ạ $\sqrt{ }$ Gịin)o:ti & -33.5 & -3 & -4 & -1 & -3 & -1 \\
\hline (p.ạ $\sqrt{ }(\underline{i})$ )no:ti & -34.0 & -4 & -4 & & -2 & \\
\hline
\end{tabular}

Step 6 (convergence) omitted.

Derivation (42) shows nati accessing a post-plosive target when $\sqrt{ }$ is not crossed. Because $/ \sqrt{ }$ te:knas/ (assuming a richness-of-the-base input without retroflexion) is a root, IDENTOO is not applicable. Figure (42) ignores the debuccalization of final $/ \mathrm{s} / \mathrm{to}[\mathrm{h}]$ if this word were pronounced in isolation.

base of free form $i$ could be defined as the free form $j$ such that $j$ contains the maximal proper subset of the grammatical features of $i$ and no conflicting features (Kager 1999: 281). 


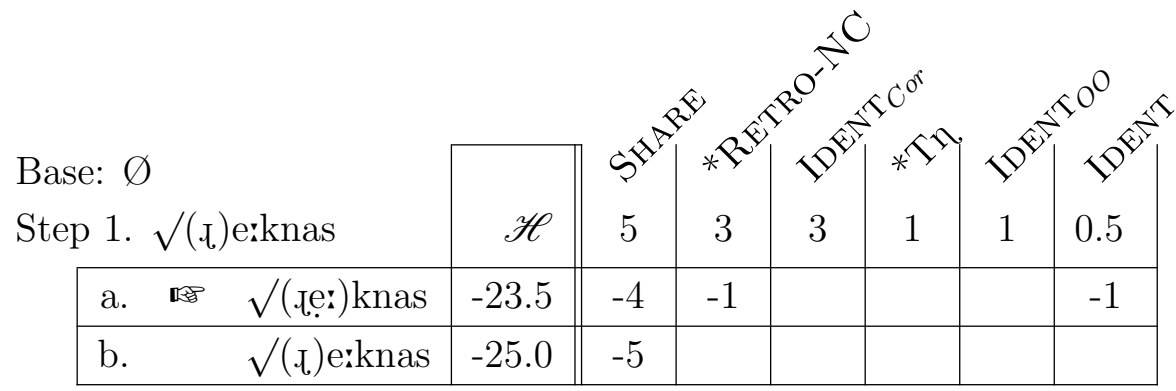

Step 2. $\sqrt{ }($ fẹ: $)$ knas

\begin{tabular}{|c|c|c|c|c|c|}
\hline a. & $\sqrt{ }($ tẹk)nas & -21.5 & -3 & -2 & -1 \\
\hline
\end{tabular}

Step 3. $\sqrt{ }($ זe:k $)$ nas

\begin{tabular}{|ll|l||c|c|c|c|c|c|}
\hline a. & $\sqrt{ }($ ヶe:kn)as & -20.5 & -2 & -2 & -1 & -1 & & -1 \\
\hline b. & $\sqrt{ }($ ๘e.k. nas & -21.0 & -3 & -2 & & & & \\
\hline
\end{tabular}

Step 4 (convergence) omitted.

Finally, when the span crosses $\sqrt{ }$ and reaches a potential post-plosive target, as in [p.- $\sqrt{ }$ a:p-no:-ti] in (43), both ${ }^{*} \mathrm{T \eta}$, and IDENT $O$ o are violated, now collectively (with IDENT and IDENT $_{\text {Cor }}$ ) outweighing SHARE. This gang effect prevents nati from reaching the target in Step 4. Vowel coalescence between preverb /pıa/ and root/a:p/ is assumed by fiat.

(43) Base: [a:pno:ti]

Step 1 omitted.

Step 2. (p.t) $\sqrt{ }$ a:pno:ti

Step 3. (p. $\sqrt{ } a:$ : $)$ pno:ti

\begin{tabular}{|l|l|l||l|l|l|l|l|l|}
\hline a. & -4 \\
\hline
\end{tabular}

Step 4. (p.l $\sqrt{\text { a:p}})$ no:ti

\begin{tabular}{|ll|l||c|c|c|c|c|c|}
\hline a. & (p. $\sqrt{ }$ a:p)no:ti & -31.0 & -4 & -3 & & & -2 & \\
\hline b. & (p. $\sqrt{ }$ a:pn $)$ o:ti & -31.5 & -3 & -3 & -1 & -1 & -3 & -1 \\
\hline
\end{tabular}

This section will now conclude with some remarks on exceptions and on the lack of previous recognition of the rule described here. As a representative passage from a grammar, Whitney (1889: section 195a) says only the following about post-plosive targets (Wackernagel 1896 says somewhat more, but the outlook for the present point is the same):

"The immediate combination of $\mathbf{n}$ with a preceding guttural or labial seems in some cases to hinder the conversion to n: thus, vṛtraghná etc., kṣubhnāti, tṛpnoti (but in Veda tṛpṇu), kṣepnú, suṣumná."

This description implies that post-plosive targets vary freely, as indeed phonologists mentioning this caveat have taken it (Steriade 1995: 52f, Hansson 2010: 182). It is the nature of 
grammars, after all, to list exceptions without tempering them with clear indications as to the robustness of the rule. To address Whitney's examples, [ $\sqrt{ }$ u,t.ta- $\sqrt{ } g^{h}$ ná: ] Vrtra-killer' follows the rule proposed here. $\left[\sqrt{ } \mathrm{ksub}^{\mathrm{f}}-\mathrm{nV}\right]$ 'shake' does not, but is entirely absent (with either $[\mathrm{n}]$ or $[n]$ ) from the present two-million-word corpus. $[\sqrt{ } \mathrm{t} . \mathrm{p}-\mathrm{NV}]$ 'be pleased', in which $\mathrm{N} \in\{\mathrm{n}, \mathrm{n}\}$, occurs eight times and breaks the rule only once. In other words, Whitney foregrounds the exception, not the rule. [ $\sqrt{ }$ kșe:p-nú] 'springing' occurs once and is a genuine exception. [su- $\sqrt{ }$ sum-nV] 'gracious' is not included in the lists above, which consider only post-plosive targets. Its counts here are 'v5' for [n] and 'v1 b1 e7' for [n]. ${ }^{9}$

$[\mathrm{su}-\sqrt{ }$ sum-nV] and two similar forms from the list of non-undergoers in (34), namely

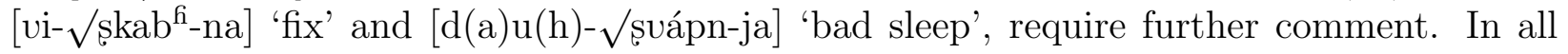
three, the trigger [s] ostensibly occupies the root, and none exhibits nati. While at first glance exceptions to the proposed generalization, in fact they follow from it. In every case, the trigger acquires its retroflexion from the prefix via ruki (section 2.2). Thus, they correspond to non-prefixed forms without nati, and the gang effect of $* \mathrm{Tn}$, or ${ }^{*} \mathrm{Nn}$ (footnote 9) with IDENT $_{O O}$ applies in the prefixed forms, properly suppressing nati.

Putting aside these three forms with ruki as explained, then, the rule, as stated above, is a near-perfect generalization. All 138 tokens with post-plosive nati have a domain of retroflexion that is root-initiated, and 1,648 of 1,650 (99.9\%) of tokens with a failure of post-plosive nati have a domain of retroflexion would have to cross $\sqrt{ }$. The only robust exceptions in this corpus are one token of $\left[\sqrt{ } \mathrm{ksse}_{\mathrm{s}} \mathrm{p}-\mathrm{nV}-\right]$ and one of $[\sqrt{ } \mathrm{t} \cdot \mathrm{p}-\mathrm{nV}$ - $]$ (against seven of $\left.\left[\sqrt{ } t_{t} \cdot \mathrm{p}-\eta \mathrm{V}-\right]\right)$, both mentioned by Whitney (1889).

\section{Boundary attenuation II: clashing spans}

As a further complication, nati also fails under certain predictable circumstances when a retroflex follows the target. For example, consider once again the preverb [p.a-], now with the root $\sqrt{ }$ nac- 'vanish' (or 'reach'). As section 3 demonstrated, [p.a-] triggers nati in a root or suffix. /p.a $\sqrt{ }$ nac-/ is no exception, as (44) reinforces.
(a) p.a- $\sqrt{ }$ nac-ja-ti 'vanishes $(3 \mathrm{~s})$ '
(b) p.a- $\sqrt{ }$ nac-ja-n-ti 'vanish $(3 \mathrm{pl})$ '
(c) p.a- $\sqrt{ }$ na:6-in-i: 'destroyer (fem.)'
(e53 vs. 0)
(d) p.á- $\sqrt{ }$ rak
'reach (aorist)'
(b2 e3 vs. 0)
(e5 vs. 0$)$
(e) p.a- $\sqrt{ }$ na:c-aj-e:-t
'destroy (3s caus. opt.)'
(v4 b1 u1 vs. 0)
(f) p.ta- $\sqrt{ }$ na:c-a
'disappearance'
(e2 vs. 0$)$
(e17 vs. 0)

But when the final consonant of $\sqrt{ }$ nac- is realized as retroflex (owing to irrelevant mor-

\footnotetext{
${ }^{9}$ Once plosives and vowels are put aside, only two non-coronals remain that are normally licit in immediately pre- $[n]$ position, namely, $[\mathrm{m}]$ and $[\mathrm{h}]$. As $[\mathrm{su}-\sqrt{ } \mathrm{s}$ sum-nV] might suggest, nati applies optionally in this context when nati crosses $\sqrt{ }$. This optionality could be implemented by giving $* N n$, which penalizes [n] immediately following a sonorant consonant, less weight than ${ }^{*} \mathrm{~T} \eta$ in a probabilistic implementation of HG (Hayes and Wilson 2008, Pater 2009b). ${ }^{*} \mathrm{~T} \eta,{ }^{*} \mathrm{~N} \eta$ can be motivated by the greater perceptibility of retroflexion following a sonorant as opposed to a plosive.
} 
phophonology), nati fails in the vast majority of instances, as shown in (45). Forms (b-c) do not appear in the present corpus, but are cited as such in the sources given ('MW' abbreviating Monier-Williams 1899). In total, the corpus contains 320 instances of $/$ pła- $\sqrt{ }$ nac- $/$. Of them, 218 have a non-retroflex ending, and nati applies in 100\% of those cases. The remaining 102 have a retroflex ending, and nati fails in $91 \%$ of those cases.
(a) (vi-)p.a- $\sqrt{ }$ naș-ta-
'vanished (past pass. part.)' (e91 vs. e9)
(b) p.a- $\sqrt{\text { naș-tum }}$
'to vanish (inf.)'
(0 vs. $0 ; \mathrm{MW}: 659)$
(c) p.a- $\sqrt{ }$ na-y-k-Ş-ja-ti 'will vanish (3s fut.)'
(0 vs. 0; Allen 1951: 946)

Moreover, the pattern suggested by the above paradigm is general. Regardless of the prefix and root involved, nati fails to cross $\sqrt{ }$ when an unblocked retroflex follows the target ('unblocked' meaning that no coronal intervenes; cf. [t] in [p.a- $\sqrt{ }$ nes-t.t] 'leader'). Additional examples are given in (46). Diagnostic forms are infrequent because the requisite set-up is quite specific, being a triggering prefix attached to a stem with an unblocked target followed by an unblocked retroflex, which in Sanskrit is unlikely to be provided by a suffix. But insofar as forms meeting these criteria are found, the generalization is supported.
(a) p.a- $\sqrt{ }$ n.t. $\quad$ 'dance forth' (v1 e32 vs. 0)
(b) pafi- $\sqrt{ }$ n.t. 'dance around' (v3 e1 vs. 0)
(c) p.a- $\sqrt{\text { najd- }}$ - 'roar'
(e1 vs. 0$)$
(d) p.ta- $\sqrt{ }$ nakş- 'approach'
(0 vs. 0 ; MW: 681)
(e) pajii- $\sqrt{ }$ nakş- 'encompass'
(0 vs. 0; Macdonell 1910: section 47)

Aside from the nine exceptional (against 91 regular) tokens of [p.a- $\sqrt{ }$ nass-ta- $]$ mentioned in (45), the only other cases in the corpus in which a prefix triggers nati in a root domain containing an unblocked retroflex are given in (47). ${ }^{10}$ These exceptions are discussed further at the end of this section.
(a) рлаa- $\sqrt{ }$ ne:-ş-
'lead forth (fut./subj.)'
(v1 b1 e2 vs. 0)
(b) p.ja- $\sqrt{ }$ na:d.j-ah
'waterways'
(e1 vs. 0)
(c) p.ta- $\sqrt{ }$ van-é:-şu
'slopes (loc. pl.)'
(v1 vs. 0)

That nati is suppressed by a following retroflex is already established in the literature (Macdonell 1910: section 47, Allen 1951: 945f, Hansson 2010: 184), though to my knowledge no formal analysis of it has been put forth. Hansson (2010: 184) suggests that it might arise from misperception, specifically, the hypocorrective misattribution of the source of the cues for retroflexion on the nasal to the surrounding retroflexes. But given the data to be presented in (48), this explanation cannot be correct: In other contexts, Sanskrit orthoepy/orthography consistently records retroflexion on nasals in inter-retroflex position.

Previous discussions do not make explicit the fact that suppression is confined to a limited morphological context. Hansson (2010: 184), for one, reports only that "[w] hen there is also

\footnotetext{
${ }^{10}$ Though it is not a verbal form, the Vedic compound $[\sqrt{ }$ svà-- $\sqrt{ }$ nata. $]$ 'sky-man' (v17 b4 e4 vs. 0) is also an exception to the analysis proposed in this section, perhaps owing to the adjacency of the target and trigger. Other compounds, such as [ $\sqrt{ }$ cikșa:- $\sqrt{ }$ nađá $]$ 'trainer, facilitator' (v3 vs. 0), follow the generalization.
} 
an /s/ or /r/ later in the word, retroflexion fails to apply" (likewise Graf 2010, Jardine 2014). ${ }^{11}$ Indeed, Macdonell (1910), whom he cites, leaves this interpretation open. Allen (1951) claims that the suppressing retroflex may be at most one vowel away from the target (on which, see below), but omits any mention of morphological conditioning.

In particular, suppression of nati by a following retroflex occurs only when the span must cross $\sqrt{ }$. Otherwise, nati applies regardless of whether a retroflex follows, as the examples in (48), among numerous others, illustrate. Such cases of non-suppression within the root-suffix complex vastly outnumber the cases of cross- $\sqrt{ }$ suppression considered above.
(a) V b.ta:fiman-é:-şu
'Brahmins (loc. pl.)'
(v2 b1 e67 vs. 0)
(b) $\sqrt{ }$ gđhi-nii-șa
'grasp (2s imp.)'
(e15 vs. 0)
(c) $\sqrt{ }$ k.t-nu-șvá
'do/make (2s imp.)'
(v26 b1 vs. 0)
(d) $\sqrt{ }$ p.t-na-k-si
'unite $(2 \mathrm{~s})$ '
(v8 b2 vs. 0)
(e) $\sqrt{ }$ p.ta:n-i-șu
'breathers (loc. pl.)'
(e7 vs. 0)
(f) $\sqrt{ }$ pu.tanna- $\sqrt{ }$ usi
'ancient rishi'
(e6 vs. 0)
(g) $\sqrt{ }$ tán-i-ş-tana
'rejoice (2pl aorist)'
(v1 vs. 0)
(h) a- $\sqrt{\text { fa:n-i-s-uh }}$
'rejoice (3pl aorist)'
(v1 vs. 0)

Descriptively, the new generalization can be summarized as in (49), whose structure mirrors (39) in section 3. As (49) implies, a gang effect with IDENT $_{O O}$ is once again in evidence.

(a) Harmony is marked across $\sqrt{ }$.

(b) Retroflexion is marked immediately preceding another domain of retroflexion.

(c) Nati applies in spite of (a) and (b), except when both apply simultaneously.

What remains to be treated is the markedness constraint implied by (b). Here, it is proposed that the failure of harmony in such cases reflects the OCP (Obligatory Contour Principle; Leben 1973, McCarthy 1986, Myers 1997). OCP ([retro]) in (50) penalizes every point of contact between two spans of retroflexion. On this approach, [p.a- $\sqrt{ }$ n.t.t], for instance, fails to undergo nati because doing so would give $*\left[\left(p_{\text {. }}\left(a_{-}-\sqrt{ } \eta_{\text {. }}\right)\left(\tau_{1}\right) \mathrm{t}\right]\right.$, which violates both OCP and IDENT $O$ O . (Other constraints in section 2, namely, FlaPOUT, IDENT OrCor $_{\text {, }}$ and $\operatorname{MAx}([$ retro $])$, prevent fusing or deleting the autosegments.)

$\operatorname{OCP}\left(\left[\right.\right.$ retro]) (abbreviated OCP): Penalize adjacent domains of retroflexion. ${ }^{12}$

\footnotetext{
${ }^{11}$ The restriction of the following suppressor to retroflex continuants as opposed to retroflex consonants in general is also unmotivated and not assumed here.

${ }^{12}$ As an anonymous reviewer points out, flapping out implies that the two retroflex spans in, say, (n)(a) are not adjacent under every interpretation. Since this article takes the segment to be the tone bearing unit for retroflexion, the OCP is interpreted accordingly: For every pair of adjacent segments $s_{1}$ and $s_{2}$, if each is linked to a distinct token of [retroflex], assign a violation to OCP. At any rate, even without strict adjacency, autosegmental systems are known to avoid overly rapid excursions. In tonology, ${ }^{*} \mathrm{HLH}$ is sometimes invoked to handle such cases (e.g. by McPherson 2014 as "Penalize two H tones separated by a single L association line"; also Cahill 2007, Hyman 2010; cf. *Trough in Yip 2002). In the present context, the rapid excursion would involve un-retroflexing and re-retroflexing the tongue tip over the course of a fraction of a segment.
} 
The analysis of suppression then runs as follows. First, the fact that a prefix such as [p.a-] normally triggers harmony across $\sqrt{ }$ continues to hold, as, (51) illustrates.

\begin{tabular}{|c|c|c|c|c|c|c|c|}
\hline Base: [nacja-] & & के & $* P^{\prime}$ & $\varphi$ & 0 & $\varphi$ & $\varphi$ \\
\hline Step 1. p(ォ)a- $\sqrt{ }$ nac-ja- & $\mathscr{H}$ & 5 & 3 & 3 & 1 & 1 & 0.5 \\
\hline a. $\quad\left(p_{f} \downarrow\right) a \sqrt{ }$ nacja- & -33.5 & -6 & -1 & & & & -1 \\
\hline b. $p($ дa) $\sqrt{ }$ nacja- & -33.5 & -6 & -1 & & & & -1 \\
\hline $\mathrm{p}($. $) \mathrm{a} \sqrt{ }$ naсja- & -35.0 & -7 & & & & & \\
\hline
\end{tabular}

Step 2 omitted.

Step 3. (p.ạ) $\sqrt{ }$ nacja-

\begin{tabular}{|ll|l||c|c|c|c|c|c|}
\hline a. & $($ p.a. $\sqrt{ }$ $)$ acja- & -30.5 & -4 & -2 & -1 & & -1 & -1 \\
\hline b. & (р.а) $\sqrt{ }$ nacja- & -31.0 & -5 & -2 & & & & \\
\hline
\end{tabular}

Second, when no $\sqrt{ }$ intervenes, an OCP violation is tolerated, as in (52). Once again, candidates with fusion and deletion are ruled out by other constraints in section $2 .{ }^{13}$

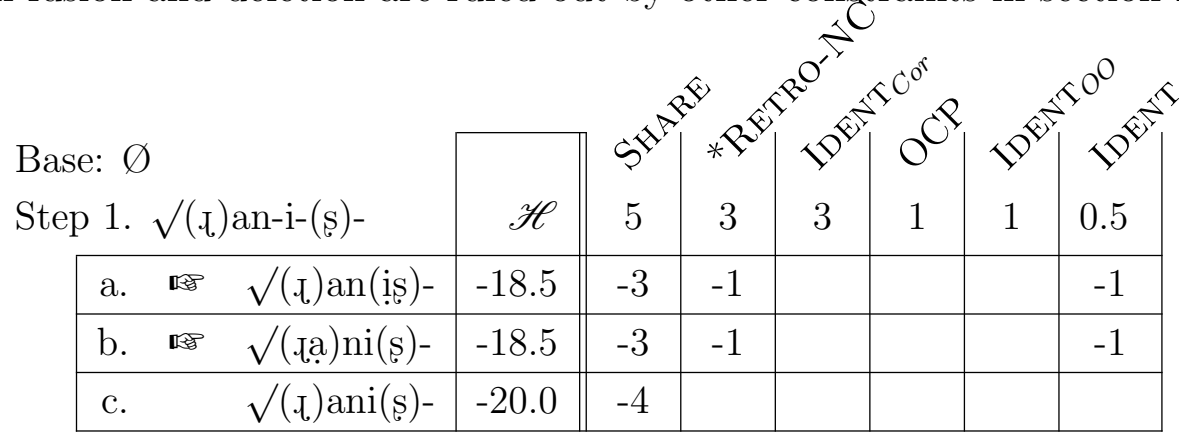

Step 2 omitted.

Step 3. $\sqrt{ }($ tạ $) n($ is $)$ -

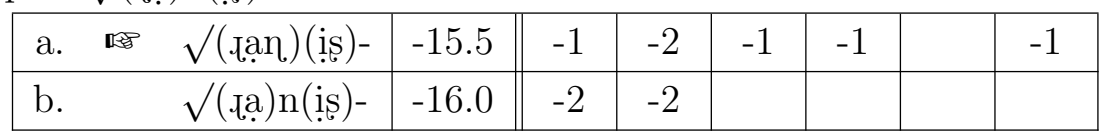

Finally, when $\sqrt{ }$ would interrupt harmony, harmony fails, thanks to OCP and the IDENT constraints collectively outweighing SHARE. In (53) Step 1, IDENT $O$ o ensures that retroflexion in the root spreads first. As Step 4, candidate (c) demonstrates, the second span of retroflexion cannot retreat across the vowel to rescue the OCP. Step 4 does not contain a candidate that involves both a retraction of retroflexion before [s] and application of nati to $/ \mathrm{n} /$, since only one change per step is possible. IDENToo thus does double duty in this

\footnotetext{
${ }^{13}$ For simplicity, the sibilant is given as retroflex in the input, though it is due to ruki. The markedness

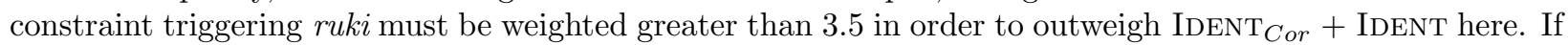
its weight is less than that of SHARE, nati precedes ruki (and subsequent assimilation of the pre-ruki vowel). If its weight is greater than that of SHARE, ruki precedes nati. In either case, the ultimate outcome is the same: The two spans expand until they abut, as illustrated.
} 
derivation, first by favoring root spreading over prefix spreading, precluding an ultimate outcome as * [(p.a. $\sqrt{ } \eta) a(s t) a-]$, and second by contributing to the gang effect with OCP.

\begin{tabular}{|c|c|c|c|c|c|c|c|}
\hline \multicolumn{8}{|l|}{ Base: [n(ạst.)a-] } \\
\hline Step 1. p(๘)a- $\sqrt{ }$ na(s-t)a- & $\mathscr{H}$ & 5 & 3 & 3 & 1 & 1 & 0.5 \\
\hline a. $\quad \mathrm{p}(\mathrm{\tau}) \mathrm{a} \sqrt{ } \mathrm{n}(\mathrm{ast}) \mathrm{a}$ & -28.5 & -5 & -1 & & & & -1 \\
\hline (p..)a $\sqrt{ }$ na(st)a- & -29.5 & -5 & -1 & & & -1 & -1 \\
\hline $\mathrm{p}($ ra $) \sqrt{ }$ na(st)a- & -29.5 & -5 & -1 & & & -1 & -1 \\
\hline $\mathrm{p}(\mathrm{\jmath}) \mathrm{a} \sqrt{ }$ na(st)a- & -31.0 & -6 & & & & -1 & \\
\hline
\end{tabular}

Steps 2-3 omitted.

Step 4. (p.ạ) $\sqrt{ } \mathrm{n}($ ast. $) a-$

\begin{tabular}{|c|c|c|c|c|c|c|c|c|}
\hline a. & (p.ạ) $\sqrt{ } n$ (ạst)a- & -24.0 & -3 & -3 & & & & \\
\hline b. & $($ p.ta $\sqrt{ } \eta)($ asst)a- & -24.5 & -2 & -3 & -1 & -1 & -1 & -1 \\
\hline c. & (ptạ) $\sqrt{ }$ na(st)a- & -27.5 & -4 & -2 & & & -1 & -1 \\
\hline
\end{tabular}

The OCP $([$ retro] $]$ ) analysis correctly predicts that nati should not be suppressed if the following span of retroflexion is removed by or or more segments from the preceding one. In

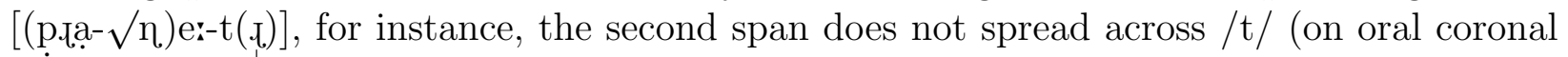
blocking, see section 2.2). Therefore, the OCP is not applicable, and nati succeeds.

Beyond harmony, the activity of $\mathrm{OCP}([$ retro] $])$ in Sanskrit is corroborated by reduplication. Consider the desiderative, which comprises a CV reduplicant prefix in which V is high as well as the suffix /-s/ (Whitney 1889: section 1,026ff). If the root is /s/-initial and no retroflex follows, the root undergoes ruki conditioned by the prefix, as in [si- $\sqrt{ }$ sa:-s- $]$ 'wish to gain' (for $\sqrt{ }$ sa: $)$ and $[\mathrm{su}-\sqrt{ }$ sup-s-] 'wish to sleep' (for $\sqrt{ }$ svap). But if the suffix undergoes ruki, ruki in the root is usually (though not always) suppressed, as in [si- $\sqrt{ }$ sayk-s-] 'wish to hang' (for $\sqrt{ }$ sajf) and [si-si: $\tau_{-S}$ - $]$ 'wish to flow' (for $\sqrt{ }$ s...).

This section will now conclude with some remarks on the locality of nati suppression. First, all examples of suppression so far have involved a target in a root. Nevertheless, some of the forms used to exemplify suppression in previous research (Macdonell 1910: section 47, Allen 1951: 945f, Hansson 2010: 184) have a somewhat different profile. These are enumerated in (54), in which ' =' indicates a compound boundary and ' $\mathrm{X}$ ' contains an unblocked trigger.
(a) $\sqrt{ }$ pu.uu $=$ niş- $\sqrt{ }$ șíd $^{\text {f }}$ - 'all-giving' (v2 vs. 0)
(b) $\quad \sqrt{ } \mathrm{X}=$ ni.f- $\sqrt{ }$ nif- $\quad$ 'X-adornment' $\quad$ (v6 e1 vs. 0$)$
(c) paji-ni- $\sqrt{ } \mathrm{st}^{\mathrm{h}} \mathrm{a}$ :- 'eminent' (e28 vs. 0)
(d) pafi-ni.-- $\sqrt{ }$ vin:a 'despondent' (e2 vs. 0)

In all of the cases in (54), the suppressed target is in a prefix. The compounds in (a-b) are handled properly by this analysis if it is assumed that each member is evaluated separately 
by $\operatorname{IDENT}_{O O}$ (e.g. for (a), the bases would be [pu.uú] and [niș $\sqrt{ }$ síd ${ }^{\text {f }}$ - $]$ with its prefix). ${ }^{14}$ Items $(\mathrm{c}-\mathrm{d})$ are cases of double prefixation in which the first prefix could trigger nati in the second, but fails, perhaps because a retroflex follows. However, these prefix pairs are likely ineligible for $n a t i$ in the first place. ${ }^{15}$

Second, one might wonder whether suppressing retroflexes are confined to roots, given that the examples of non-suppression mostly involve inflectional suffixes. This is not the case, as properly captured by the analysis. Prefixes suppress in (54), the suffix [-s] suppresses in (45), and in every other case in (45), the suppressing consonant, though ostensibly located in the root, acquires its retroflexion from a suffix.

Third, all examples of (successful) suppression in this section involve a morphemeinitial target. The analysis here predicts that suppression should also be possible for nonmorpheme-initial targets. Forms confirming or disconfirming this prediction are rare, owing to the combined infrequencies of the requisite parts, namely, a triggering prefix, a root beginning with a vowel or non-coronal followed by a dental nasal, and a suffix containing an unblocked retroflex. One such case was cited in (47), namely, [p.̦a- $\sqrt{ }$ van-é:-șu]. Suppression fails in this case, but this single token is not particularly compelling, since other causes for the failure are conceivable (e.g. next paragraph).

A final question concerns whether the suppressing retroflex can be any distance from the target. All of the examples of suppression in this section involve a suppressor that is at most $\breve{V}_{0}^{1} \mathrm{C}_{0}^{2}$ away from the target, where $\breve{\mathrm{V}}$ is a short vowel. No case of suppression across a long vowel or multiple syllables was found. What's more, all of the exceptions to suppression in (47) involve a target and suppressor straddling a long vowel. Since diagnostic data are sparse, it will be left unresolved here whether this generalization is principled or accidental. If it were principled, it could indicate that leftward spreading from retroflexes (across non-coronals) is not unchecked, as implied by section 2.2 , but rather limited to a single vocalic mora. On the present approach, a constraint requiring a preceding vowel to license retroflexion (cf. RETRO/V_ in Steriade 1995) could dominate a constraint forbidding leftward spreading (e.g. InITial(feat) in McCarthy 2009b) to achieve minimal leftward spreading.

Suppression also fails regardless of distance when the would-be suppressor is derived by external sandhi, as predicted by the present analysis given that the nati span remains stem-

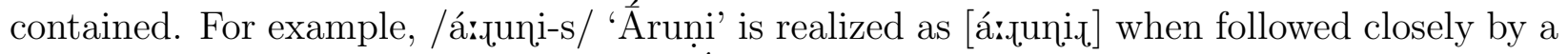
voiced-initial word, as in [á:ıuni.đ a:ha] 'Áruni said'. While there remains more philological work to be done on suppression, this article is not the place to do so. This section has shown that nati suppression, previously unanalyzed, can be accommodated by the proposed

\footnotetext{
${ }^{14} \mathrm{Nati}$ applies less reliably in compounds in general (section 3 and footnote 10), though in this case an argument can still be made for suppression: The initial members of the compounds in (a-b) comprise [pưú], [sahás.ða], [candıá], and [vaıșá]. In every one of the 12 tokens in the Rg-Veda in which one of these initials attaches to a /nV[retro]/ base, nati fails. In every one of the eight tokens in which one of these initials attaches to any other $/ \mathrm{n}$ /-initial base, nati succeeds, a significant difference (Fisher's exact test $p<.0001$ ).

${ }^{15}$ Nati application across certain preverbs is unreliable in Epic Sanskrit. Tellingly, though only four tokens of /paji-/ before /ni-/ or /nis-/ are attested without a following retroflex, all lack nati: [pại-ni- $\sqrt{ } g^{\mathrm{h}}$ nanta], [pa.ji-nic- $\sqrt{ }$ cit $(j) a(m)]$, and [pa.ji-nih- $\sqrt{ }$ cvasan]
} 
account of nati by adding a single constraint, $\mathrm{OCP}([$ retro] $])$.

\section{Analytical comparisons}

The analysis of nati proposed in this article relies on output-output (OO) correspondence in serial Harmonic Grammar (HG). This section considers four alternative approaches (namely, morphological indexation, constraint conjunction, level ordering, and non-serial HG), each with the potential obviate one or more of these mechanisms (OO, serialism, and/or HG). It is argued that all four alternatives are untenable or pathological.

\subsection{Morphologically indexed constraints}

As established in section 3-4, harmony affects a post-plosive or pre-retroflex target unless it has to cross a left root boundary (' $\sqrt{ }$ ') to reach it. In the proposed analysis, IDENT $O$ O tempers the benefit of spreading into the root domain. But consider an alternative approach in OT by which prefixes are treated as weak triggers for harmony, in the sense that they access fewer targets than root triggers do. Root control is common in harmony systems (Clements 1980 et seq.), and affix-triggered harmony can be penalized directly (e.g. Kenstowicz 2009). Nevertheless, the nati data in section 3-4 cannot be characterized as affix weakness: A root trigger is comparably weak when its span crosses $\sqrt{ }$, as seen in compounds (e.g. (35), (36), (54)). Thus, the descriptive generalization is not that affixes are weak triggers, but that spreading is weakened by the left edges of roots. ${ }^{16}$

Rather than treating affixes as weak, a related OT strategy might treat roots or stems as strong. Assume that 'stem' here refers to the root-suffix complex. Generic SpREAD([retro]), as defined in (55), penalizes unharmonized segments regardless of their morphological affiliation. SPREAD $([\text { retro] }])_{\text {Stem }}(56)$ penalizes unharmonized segments within a stem when the head of the span occupies the same stem. ${ }^{17}$

$\operatorname{SpREAD}\left(\left[\right.\right.$ retro]): For every [retroflex] token $a_{1}$, penalize every segment to which $a_{1}$ is not associated.

$\operatorname{SpREAD}([\text { retro }])_{\text {Stem }}$ : For every [retroflex] token $a_{1}$ whose head is in stem $b_{1}$, penalize every segment in $b_{1}$ to which $a_{1}$ is not associated.

\footnotetext{
${ }^{16}$ A morphological version of *DePendent-HeAd (Mullin 2011) would be untenable here for this same reason, since it defines weakness according to properties of the head of the span (cf. also Walker 2005).

${ }^{17}$ The formulation of SPREAD Stem here assumes headed spans (McCarthy 2004). An alternative formulation might refer only to stem containment, e.g., "for every [retroflex] span contained within a stem, penalize every segment within that stem to which the span is not associated." The problem with this approach is that it predicts root harmony to be suppressible when a prefix is attached. For example, with SPREAD Stem $\gg{ }^{*} \operatorname{Tn},\left[\sqrt{ }(\right.$ «e:kn)as $]$ wins, as it should, but nati fails if the form is prefixed, e.g. ${ }^{*}[\mathrm{~s}(\mathrm{u}-\sqrt{ }$ eẹ.k. nas $]$. The prefix provides an 'escape hatch' for the span, voiding all of the violations of SPREAD Stem once the span is no longer stem-contained and thus turning the decision over to ${ }^{*} \mathrm{Tn}$. Even if this situation could be remedied with additional constraints in Sanskrit, it would remain as a typological pathology.
} 
SPREAD $([\text { retro }])_{\text {Stem }} \gg *$ Tr $\gg$ SPREAD $([$ retro $])$ handles the morphological conditioning properly, as in (57) and (58), in which heads are underlined. In (57), stem-initiated harmony is strong, compelling violation of ${ }^{*} \mathrm{~T} \eta$. In (58), by contrast, harmony initiated from outside of the stem is weak, and ${ }^{*} \mathrm{~T} \eta$ decides.

\begin{tabular}{|c|c|c|c|c|}
\hline$\sqrt{ }(\underline{I}$. $)$ exknas & FLAPOUT & SPREAD $([\text { retro }])_{\text {Stem }}$ & $*^{*} \mathrm{Tn}$ & $\operatorname{SpREAD}([$ retro $])$ \\
\hline 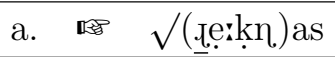 & & $* *$ & * & $* *$ \\
\hline$\sqrt{ }($ fẹ:k)nas & & $* * * !$ & & $* * *$ \\
\hline$\sqrt{ }(\underline{\text { I. }})$ exknas & & $* * * ! * *$ & & $* * * * *$ \\
\hline d. $\quad \sqrt{ }($ zẹ:kna $) \mathrm{s}$ & $* !$ & * & $*$ & * \\
\hline
\end{tabular}

$(58)$

\begin{tabular}{|c|c|c|c|c|}
\hline $\mathrm{p}(\underline{\underline{f}}) \mathrm{a}-\sqrt{ }$ a:pno:ti & FlaPOUT & $\operatorname{SPREAD}([\text { retro }])_{\text {Stem }}$ & ${ }^{*} \operatorname{T\eta }$ & $\operatorname{SPREAD}([$ retro $])$ \\
\hline a. $\quad(p . \underline{v} \sqrt{a}: p) n o: t i$ & & & & $* * * *$ \\
\hline $\mathrm{p}(\underline{\underline{I}}) \sqrt{ }$ a:pno:ti & & & & $* * * * ! * * *$ \\
\hline (p. & & & & $* * * *$ !** \\
\hline (p.lva:pl)o:ti & & & $* !$ & $* * *$ \\
\hline
\end{tabular}

This analysis covers the core boundary-attenuation facts discussed in this article without invoking serial HG or output-output correspondence. Nevertheless, it has drawbacks unshared by the HG analysis, including too-many-solutions pathologies. First, since stem indexation relies on headed spans (footnote 17), an alternative to spreading within the stem is shifting the head outside of the stem. In (59), candidate (d) should win (as it does in (57); see also section 3 ), but (a), with head-shifting and weak spreading, prevails.

\begin{tabular}{|c|c|c|c|c|}
\hline \multicolumn{2}{|c|}{ su- $\sqrt{ }(\underline{\jmath})$ exknas } & $\operatorname{SPREAD}([\text { retro }])_{\text {Stem }}$ & ${ }^{*} \mathrm{Tn}$ & $\operatorname{SPREAD}([$ retro $])$ \\
\hline a. $\boldsymbol{x}$ & $\mathrm{s}(\mathrm{u} \sqrt{ }$ dẹ:k)nas & & & $* * * *$ \\
\hline $\mathrm{b}$. & $\mathrm{s}(\underline{\mathrm{u}} \sqrt{ } \underline{\underline{\underline{d}} \mathrm{e}} \mathrm{k}) \mathrm{nas}$ & $* ! * *$ & & $* * * *$ \\
\hline c. & $\mathrm{s}(\underline{\underline{u}} \sqrt{ }$ tẹ:ḳn)as & & $* !$ & $* * *$ \\
\hline $\mathrm{d}$. & 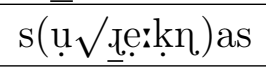 & $* ! *$ & $*$ & $* * *$ \\
\hline e. & su $\sqrt{ }(\underline{\text { tẹkn }})$ as & $* ! *$ & $*$ & $* * * *$ \\
\hline f. & $\mathrm{su} \sqrt{ }(\underline{\underline{e}: \mathrm{k}}) \mathrm{nas}$ & $* ! * *$ & & $* * * * *$ \\
\hline
\end{tabular}

This situation could be patched in Sanskrit by ranking a constraint requiring head posi-

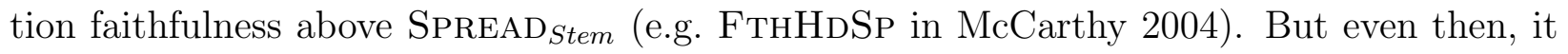
remains as an unwanted typological prediction, given the factorial typology. More generally, SPREAD/ALIGN constraints in non-serial OT exhibit a number of pathologies, some of which are solved by serialism (see Wilson 2003, McCarthy 2004, 2009b, 2011, and Kimper 2011).

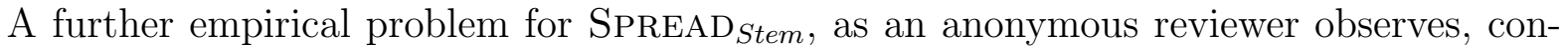
cerns forms such as [vi- $\sqrt{ }$ skab $^{\text {fi }}$-na-] 'prop' (from root $\sqrt{ }$ skab $^{\text {f }}$ ), in which $[s]$ occupies the stem 
but fails to trigger strong spreading to post-plosive $/ \mathrm{n} /$ (section 3 ). The OO-based account properly handles such cases without any additions, since the unprefixed base is [ $\sqrt{ }$ skab $^{\mathrm{h}}$-na- $]$,

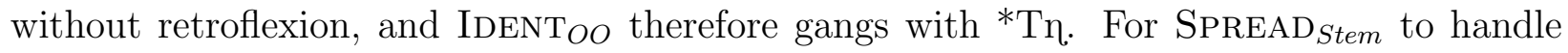
such cases, the head of retroflexion would have to escape to the prefix, but that behavior is undesirable in other contexts, as illustrated by (59).

A more general problem for morphological indexation is that the domain has to be stipulated. Why is 'Stem' the root plus suffixes, as opposed to, say, the root plus prefixes, or just the root, or the root plus certain suffixes, and so forth? Are these other constraints in the constraint set? The OO-based account is more restrictive and arguably more explanatory. Whenever a free base (footnote 8) is available, it exerts analogical force via correspondence. In the case of $\left[v i-\sqrt{ } s_{k a b}{ }^{h}-n a-\right]$, otherwise identical forms without the prefix are available $\left(\sqrt{ }\right.$ skab $^{\mathrm{h}}$-na-), so IDENT $O$ OO (ganging with other IDENT) precludes nati. No morphological domain has to be stipulated as part of any constraint.

\subsection{Constraint conjunction}

The analyses in section 3-4 relied on gang effects and hence on HG. In section 3, for instance, spreading to a post-plosive target (in violation of ${ }^{*} \mathrm{~T} \eta$ ) is grammatical but only when doing so would not also violate $\operatorname{IDENT}_{O O}([$ retro $])$. This ostensible gang effect could alternatively be analyzed in OT using constraint conjunction. For this case, IDENT $O \&^{*}$ Tn could be fused into a single, hybrid constraint local to some domain (Smolensky 1995). Similarly, for the gang effect in section 4 , the conjunction IDENT Oo $_{\text {\&OCP }}$ could be employed.

The domain of these conjunctions cannot be the word: The constraint would then be violated (erroneously) even if the violations of IDENT $_{O O}$ and ${ }^{*} \mathrm{Tn}$. (or the OCP) came from two unrelated loci of retroflexion in the word, as in compounds. ${ }^{18}$ It also cannot be the root, since targets often occupy suffixes. One potentially viable domain is the segment, as in (60) and (61). For this domain to work, 'local to the segment' must mean that the segment merely participates in the violating structure, not that it comprises or contains it. ${ }^{*} \mathrm{Tn}$, after all, can only be evaluated with respect to pairs of segments. If this looser notion of locality is unacceptable, the domain could still be taken to be the biphone, although the latter is not a phonological constituent.

$(60)$

\begin{tabular}{|c|c|c|c|c|}
\hline $\begin{array}{l}\text { Base: [a:pno:ti] } \\
\text { p(๘)a- } \sqrt{ } \text { a:p-no:-ti }\end{array}$ & $\left(\mathrm{IDENT}_{O O} \&^{*} \mathrm{T \eta}\right)_{s e g}$ & SHARE & IDENT $_{O O}$ & $:$ \\
\hline a. $\quad(p . \downarrow \sqrt{ } a ̣: p) n o: t i$ & & -4 & -2 & \\
\hline b. $\quad$ (p.ı $\sqrt{ }$ ạ:pn)orti & -1 & -3 & -3 & -1 \\
\hline $\begin{array}{ll}\text { c. } & \text { (р. }) \sqrt{ } \text { a:pnorti }\end{array}$ & & -6 & & \\
\hline
\end{tabular}

\footnotetext{
${ }^{18}$ An example is $\left[\right.$ p.a- $\sqrt{ }$ naja $=\sqrt{ }$ g.jah-an $=\sqrt{ }$ a: $: \mathrm{t}^{\mathrm{h}}$-a:ja] 'for the purpose $($ artha) of seizing $($ grahana $)$ affection (?) (pranaya)' (e1 vs. 0), in which the OCP violation in grahanāarthāya is irrelevant for pranaya.
} 


\begin{tabular}{|c|c|c|c|c|}
\hline $\begin{array}{l}\text { Base: [n(ast)am] } \\
\text { p(ı)a- } \sqrt{ } \text { nac-ta-m }\end{array}$ & $\left(\text { IDENT }_{O O} \& \mathrm{OCP}\right)_{s e g}$ & SHARE & IDENT $_{O O}$ & $\mathrm{OCP}$ \\
\hline a. (p.̦a $\sqrt{ } \mathrm{n}($ asst)am & & -4 & & \\
\hline (p.la $\sqrt{ } \eta) a(s t) a m$ & & -4 & -2 & \\
\hline (p.ạ) $\sqrt{ }$ na (st)am & & -5 & -1 & \\
\hline 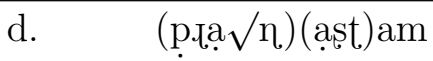 & -1 & -3 & -1 & -1 \\
\hline
\end{tabular}

At any rate, even putting aside issues of locality, conjunction is known to be highly pathological (Pater 2009a and references therein). For example, (IDENT(voice)\&NoCodA) IDENT(voice) produces a pathological grammar in which voicing is neutralized in onsets but not in codas (Ito and Mester 1998).

Second, viability aside, the conjunction analysis is arguably less elegant than the HG analysis. Consider the respective constraint hierarchies in (62) and (63). Conjunction requires extra, complex constraints to accomplish what is handled by simple constraints alone in $\mathrm{HG}$, albeit with weighting. Moreover, the complex constraints are formally redundant. Both contain IDENT $_{O O}$, and all four conjuncts have [retro] as a predicate. While these properties make sense for Sanskrit, in terms of pure formalism, they are coincidences. The theory could just as easily encode a language with these conjuncts indexed to unrelated features, such as $\left(\operatorname{IDENT}_{O O}([\text { retro }]) \& O C P([\text { labial }])\right)_{\text {seg }}$.

$$
\begin{aligned}
& \left(\text { IDENT }_{O O} \& * \text { Tn }\right)_{\text {seg }},\left(\text { IDENT }_{O O} \& \mathrm{OCP}\right)_{\text {seg }} \gg \mathrm{SHARE} \gg \mathrm{IDENT}_{O O},{ }^{*} \mathrm{~T} \eta, \mathrm{OCP} \\
& \mathrm{SHARE}>\mathrm{IDENT}_{O O}={ }^{*} \mathrm{~T} \eta=\mathrm{OCP}
\end{aligned}
$$

In conclusion, a conjunction analysis may be possible under certain assumptions about locality. It would not obviate the need for output-output correspondence (or some suitable replacement), but would provide an OT alternative to ganging in HG. However, even putting aside concerns about locality and typology, conjunction requires a more complex and redundant constraint set than serial HG does in this case.

\subsection{Stratal OT}

Third, consider a cyclical version of OT that interleaves phonological evaluation with affixation and compounding. This approach is untenable if the ranking is fixed across cycles, since it cannot implement the patterns analyzed as gang effects in section 3-4 (cf. section 5.2). However, stratal OT (Kiparsky 2000, Bermúdez-Otero to appear), in which levels can have different rankings, is more promising. Assume two levels, Stem and Word, such that prefixes are integrated in the Word. In the Stem, SHARE $\gg{ }^{*}$ Tn, therefore nati affects a post-plosive target. In the Word, the ranking is reversed, ${ }^{*} \mathrm{~T} \eta \gg$ SHARE, such that a newly introduced trigger can no longer access a post-plosive target.

This ranking as it stands erroneously undoes the retroflexion of a post-plosive target that underwent nati in the Stem. Take $/ \sqrt{ }$ te:knas/. In the Stem, it becomes $[\sqrt{ }$ te:knas]. But in the Word, nati is undone by now dominant $* T n$, leaving $*[\sqrt{ }$ te:knas $]$. Adding 
$\operatorname{MaxLink}([$ retro]), which penalizes deleting an association line to [retro] (cf. Jurgec 2011), solves this problem, preserving [n] that arises in the Stem. MAx([retro]) alone would not work, as the span could retreat without deleting. The rankings are given in (64).

$$
\begin{array}{ll}
\text { Stem level: } & \text { MAXLink }([\text { retro }]) \gg \text { SHARE } \gg * T r \\
\text { Word level: } & \text { MAXLink }([\text { retro }]) \gg * T \eta \text { Thare }
\end{array}
$$

The OCP effects in section 4 would also require more than flipping SHARE and the OCP.

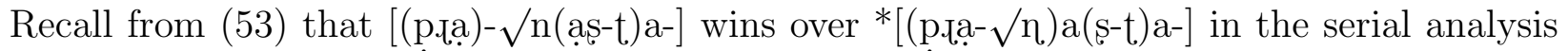
because the latter would require two changes in one step. Thus, retroflexion cannot retreat

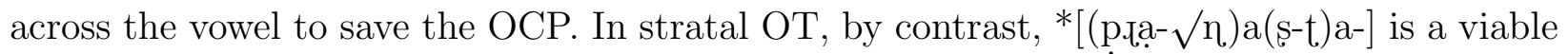
contender. It could be ruled out by adding a constraint, say, LicEnse, that penalizes a retroflex consonant not immediately preceded by a retroflex vowel, as in (65). (License must be dominated by MAX, DeP, etc., not shown.)

$$
\begin{array}{ll}
\text { Stem level: } & \text { LICENSE } \gg \text { SHARE } \gg \text { OCP } \\
\text { Word level: } & \text { LiCENSE } \gg \text { OCP } \gg \text { SHARE }
\end{array}
$$

In sum, an analysis of the facts in section 3-4 may be possible in stratal OT, though not without additional constraints. The serial HG analysis has the further virtue of requiring only a single, fixed ranking for the language, with arguable benefits for learnability and restrictiveness. Moreover, the stratal analysis requires potentially problematic assumptions about the morphology, since (often highly lexicalized) prefixation and compounding must follow (even inflectional) suffixation. With $\operatorname{IDENT}_{O O}$, a form such as [p.̨a $\sqrt{ }$ hino:ti] stands in correspondence with $[\sqrt{ }$ hino:ti $]$ simply because the former contains the latter and both are free. It does not require prefixation to follow inflection anywhere in the grammar.

\subsection{Non-serial Harmonic Grammar}

Finally, as mentioned in section 5.1, serialism avoids a number of pathologies exhibited by pro-spreading constraints in classical OT/HG. Since the analysis here depends on gang effects (section 3), serial HG rather than OT was employed. Serial HG was also favored over classical HG because the latter, while able to implement ganging, is perhaps even more pathological than classical OT when it comes to harmony, predicting what might be called cut-off-point effects (Legendre et al. 2006, Pater et al. 2007).

A classical HG cut-off-point pathology is illustrated by the grammar in (66) and (67). In this language, a blocker / $\mathrm{t} /$ is deleted to permit retroflexion to spread further in service of

SHARE (already a pathology), but only if more than seven segments would otherwise remain unharmonized. The cut-off could not only be seven, but any number, as determined by the ratio of the weight of MAX to that of Share. Since harmony is myopic in serial HG, cut-off-point pathologies of this type do not occur (Pater et al. 2007: 21). 
$(66)$

\begin{tabular}{|c|c|c|c|c|}
\hline (st)amamama & $\mathscr{H}$ & $\begin{array}{c}\text { FLAPOUT } \\
9\end{array}$ & $\begin{array}{c}\text { MAX } \\
7.5\end{array}$ & $\begin{array}{c}\text { Share } \\
1\end{array}$ \\
\hline a. (st)amamama & -7.0 & & & -7 \\
\hline (șạmạmạmạa) & -7.5 & & -1 & \\
\hline (ștạmạmạmạa) & -9.0 & -1 & & \\
\hline
\end{tabular}

\begin{tabular}{|c|c|c|c|c|c|}
\hline \multicolumn{2}{|c|}{ (șt)amamamam } & $\mathscr{H}$ & $\begin{array}{c}\text { FLAPOUT } \\
9\end{array}$ & $\begin{array}{c}\text { MAX } \\
7.5\end{array}$ & $\begin{array}{c}\text { SHARE } \\
1\end{array}$ \\
\hline a. & (șạạạạmạạm) & -7.5 & & -1 & \\
\hline b. & (st)amamamam & -8.0 & & & -8 \\
\hline c. & (stạmạmạmạạ) & -9.0 & -1 & & \\
\hline
\end{tabular}

\section{Conclusion}

Sanskrit retroflex spreading is attenuated by left root boundaries, such that stem-internal triggers access more targets than stem-external triggers. At least two independent processes demonstrate this attenuation. First, only stem-internal triggers access post-plosive targets. Second, only stem-internal triggers access pre-retroflex targets. These restrictions reveal the activity of two markedness constraints, ${ }^{*}$ Tn and the OCP. Permitted to gang with IDENTOO in serial HG, they implement the observed subset relation among triggers. Other possible approaches, including morphological indexation, constraint conjunction, and non-serial HG, were argued to be untenable or pathological. Beyond introducing and analyzing these domain conditions on nati, this article also presented a novel analysis of the basic rule that simplifies previous constraint-based analyses.

\section{References}

Allen, W. Sidney. 1951. Some prosodic aspects of retroflexion and aspiration in Sanskrit. Bulletin of the School of Oriental and African Studies 13.939-946.

Allen, W. Sidney. 1953. Phonetics in ancient India. Oxford University Press.

Anderson, Stephen. 1974. The organization of phonology. Academic Press.

Archangeli, Diana, and Douglas Pulleyblank. 1994. Grounded phonology. Cambridge, MA: MIT Press.

Arsenault, Paul Edmond. 2012. Retroflex consonant harmony in South Asia. Doctoral Dissertation, University of Toronto.

Avery, Peter, and Keren Rice. 1989. Segment structure and coronal underspecification. Phonology 6.179-201.

Avery, Peter, and Keren Rice. 1991. On the relationship between laterality and coronality. 
The special status of coronals, ed. by Carole Paradis and Jean-François Prunet. San Diego, CA: Academic Press.

Baković, Eric. 2000. Harmony, dominance and control. Doctoral Dissertation, Rutgers University.

Beguš, Gašper. 2012. The RUKI-rule in the Rigveda. Thesis, University of Ljubljana.

Benua, Laura. 1995. Identity effects in morphological truncation. Papers in Optimality Theory [Occasional Papers 18], ed. by Jill Beckman, Laura Walsh Dickey, and Suzanne Urbanczyk, volume 18, 77-136. Amherst, MA: University of Massachusetts.

Benua, Laura. 1997. Transderivational identity: Phonological relations between words. Doctoral Dissertation, University of Massachusetts, Amherst.

Bermúdez-Otero, Ricardo. To appear. Stratal Optimality Theory. Oxford University Press.

Bhat, D.N. Shankara. 1973. Retroflexion: An areal feature. Working Papers on Language Universals 13.27-67.

Boersma, Paul, and Silke Hamann. 2005. The violability of backness in retroflex consonants. Rutgers Optimality Archive 713.

Böhtlingk, Otto. 1887. Pânini's Grammatik. Leipzig: H. Haessel.

Brugmann, Karl. 1897. Vergleichende Laut-, Stammbildungs-, und Flexionslehre der indogermanischen Sprachen, volume 1. Strassburg: Karl J. Trübner, 2 edition.

Burrow, Thomas. 1973. The Sanskrit language. London: Faber and Faber.

Butcher, Andrew. 1995. The phonetics of neutralisation: The case of Australian coronals. Studies in general and English phonetics: Essays in honour of Professor J.D. O'Connor, ed. by J. Windson, 10-38. London: Routledge Press.

Cahill, Mike. 2007. More universals of tone. Dallas, TX: SIL International.

Cardona, George. 2003. Sanskrit. The Indo-Aryan languages, ed. by George Cardona and Danesh Jain, 104-160. New York \& London: Routledge.

Catford, J. C. 2001. On Rs, rhotacism and paleophony. Journal of the International Phonetic Association 31.171-185.

Cathcart, Chundra. 2012. Articulatory variation of the alveolar tap and implications for sound change. UC Berkeley Phonology Lab Annual Report 76-110.

Cho, Young-mee Yu. 1991. On the universality of the coronal articulator. Phonetics and Phonology 2.159-179.

Clements, G. N. 1980. Vowel harmony in nonlinear generative phonology. Bloomington, Indiana: Indiana University Linguistics Club.

Clements, G. N., and Elizabeth V. Hume. 1995. The internal organization of speech sounds. The handbook of phonological theory, ed. by John A. Goldsmith, 245-306. Oxford: Blackwell.

Collinge, N. E. 1965. Some linguistic paradoxes. Journal of Linguistics 1.1-12.

Dart, Sarah. 1991. Articulatory and acoustic properties of apical and laminal articulations. UCLA Working Papers in Phonetics 79.1-155.

Dart, Sarah, and Paroo Nihalani. 1999. The articulation of Malayalam coronal stops and nasals. Journal of the International Phonetic Association 29.129-142. 
Dave, Radhekant. 1977. Retroflex and dental consonants in Gujarati: A palatographic and acoustic study. Annual Report of the Institute of Phonetics, University of Copenhagen $11.27-155$.

Emeneau, Murray B. 1939. The vowels of the Badaga language. Language 15.43-47.

Flemming, Edward. 1995a. Auditory representations in phonology. Doctoral Dissertation, University of California, Los Angeles. Published 2002, London \& New York: Routledge.

Flemming, Edward. 1995b. Vowels undergo consonant harmony. Paper presented at the Trilateral Phonology Weekend 5, University of California, Berkeley.

Flemming, Edward. 2003. The relationship between coronal place and vowel backness. Phonology 20.335-373.

Gafos, Adamantios I. 1999. The articulatory basis of locality in phonology. New York, NY: Garland Publishing.

Graf, Thomas. 2010. Logics of phonological reasoning. Master's thesis, University of California, Los Angeles.

Grammont, Maurice. 1950. Traité de phonétique. Paris: Delgrave.

Halle, Morris, Bert Vaux, and Andrew Wolfe. 2000. On feature spreading and the representation of place of articulation. Linguistic Inquiry 31.387-444.

Hamann, Silke Renate. 2003. The phonetics and phonology of retroflexes. Doctoral Dissertation, University of Utrecht.

Hansson, Gunnar Ólafur. 2001. Theoretical and typological issues in consonant harmony. Doctoral Dissertation, University of California, Berkeley.

Hansson, Gunnar Ólafur. 2010. Consonant harmony: Long-distance interaction in phonology. UC Publications in Linguistics. University of California Press.

Hayes, Bruce, and Colin Wilson. 2008. A Maximum Entropy model of phonotactics and phonotactic learning. Linguistic Inquiry 39.379-440.

Howard, Irwin. 1973. A directional theory of rule application in phonology. Doctoral Dissertation, Massachusetts Institute of Technology.

Humbert, Helga. 1995. Phonological segments: Their structure and behaviour. The Hague: Holland Academic Graphics.

Hyman, Larry M. 2002. Is there a right-to-left bias in vowel harmony? Presented at the 9th International Phonology Meeting, Vienna.

Hyman, Larry M. 2010. Amazonia in the typology of tone systems. UC Berkeley Phonology Lab Annual Report 376-394.

Ito, Junko, and Armin Mester. 1998. Markedness and word structure: OCP effects in Japanese. MS., University of California, Santa Cruz.

Jäger, Gerhard, and Anette Rosenbach. 2006. The winner takes it all - almost: Cumulativity in grammatical variation. Linguistics 44.937-971.

Jardine, Adam. 2014. Computationally, tone is different. MS., submitted, University of Delaware.

Johnson, C. Douglas. 1972. Formal aspects of phonological descriptions. The Hague: Mouton. Jurgec, Peter. 2011. Icy targets. MS., Meertens Institute, Amsterdam. 
Kager, René. 1999. Optimality Theory. Cambridge, U.K.: Cambridge University Press.

Kaplan, Aaron F. 2008. Noniterativity is an emergent property of grammar. Doctoral Dissertation, University of California, Santa Cruz.

Kaun, Abigail. 2004. The phonetic foundations of the rounding harmony typology. Phonetically based phonology, ed. by Bruce Hayes, Robert Kirchner, and Donca Steriade, 87-116. Cambridge: Cambridge University Press.

Kaun, Abigail R. 1993. The coronal underspecification hypothesis. UCLA Occasional Papers in Linguistics 13.69-108.

Kenstowicz, Michael. 1996. Base-identity and uniform exponence: Alternatives to cyclicity. Current trends in phonology: Models and methods, ed. by J. Durand and B Laks, 363-93. CNRS, Paris X, and the University of Salford: University of Salford Publications.

Kenstowicz, Michael J. 2009. Two notes on Kinande vowel harmony. Language Sciences $31.248-270$.

Kimper, Wendell A. 2011. Competing triggers: Transparency and opacity in vowel harmony. Doctoral Dissertation, University of Massachusetts-Amherst.

Kiparsky, Paul. 1981. Vowel harmony. MS., MIT, Cambride, MA.

Kiparsky, Paul. 1985. Some consequences of lexical phonology. Phonology 2.85-138.

Kiparsky, Paul. 2000. Opacity and cyclicity. The Linguistic Review 17.351-367.

Kiparsky, Paul, and Karl Pajusalu. 2003. Towards a typology of disharmony. The Linguistic Review 20.217-241.

Krämer, Martin. 2003. Vowel harmony and correspondence theory. Walter de Gruyter.

Krull, Diana, Björn Lindblom, Bang-er Shia, and David Fruchter. 1995. Cross-linguistic aspects of coarticulation: An acoustic and electropalatographic study of dental and retroflex consonants. Proceedings of the XIIIth International Congress of Phonetic Sciences 3.436439.

Ladefoged, Peter. 1964. A phonetic study of West African languages: An auditoryinstrumental survey. Cambridge, U.K.: Cambridge University Press.

Langendoen, Terence D. 1968. The London School of linguistics: A study in the linguistic theories of B. Malinowski and JR Firth. Cambridge, MA: MIT Press.

Leben, William Ronald. 1973. Suprasegmental phonology. Doctoral Dissertation, Massachusetts Institute of Technology.

Legendre, Géraldine, Yoshiro Miyata, and Paul Smolensky. 1990. Harmonic grammar: A formal multi-level connectionist theory of linguistic well-formedness: Theoretical foundations. Technical Report, University of Colorado, Boulder, Department of Computer Science.

Legendre, Géraldine, Antonella Sorace, and Paul Smolensky. 2006. The Optimality TheoryHarmonic Grammar connection. The harmonic mind: From neural computation to Optimality-Theoretic grammar, ed. by Paul Smolensky and Géraldine Legendre, 339402. Cambridge, MA: Massachusetts Institute of Technology Press.

Macdonell, Arthur Anthony. 1910. Vedic grammar. Strassburg: Trübner.

Masica, Colin P. 1993. The Indo-Aryan languages. Cambridge, U.K.: Cambridge University 
Press.

McCarthy, John. 1986. OCP effects: Gemination and antigemination. Linguistic Inquiry 17.207-263.

McCarthy, John. 2005. Optimal paradigms. Paradigms in phonological theory, ed. by Laura Downing, T. A. Hall, and Renate Raffelsiefen, 170-210. Oxford University Press.

McCarthy, John. 2009a. The P-Map in Harmonic Serialism. MS., University of Massachusetts, Amherst.

McCarthy, John, and Alan Prince. 1993. Prosodic morphology I: Constraint interaction and satisfaction. MS, University of Massachusetts-Amherst and Rutgers University. Distributed as Rutgers Optimality Archive 482. Available at http://roa.rutgers . edu/view . php3?id=590.

McCarthy, John J. 2004. Headed spans and autosegmental spreading. Linguistics Department Faculty Publication Series 42.1-35.

McCarthy, John J. 2008. The gradual path to cluster simplification. Phonology 25.271-319.

McCarthy, John J. 2009b. Harmony in Harmonic Serialism. Linguistics Department Faculty Publication Series 41.1-52.

McCarthy, John J. 2011. Autosegmental spreading in Optimality Theory. Tones and features: Phonetic and phonological perspectives, ed. by John A. Goldsmith, Elizabeth Hume, and W. Leo Wetzels, 195-222. Berlin and Boston: De Gruyter Mouton.

McPherson, Laura. 2014. Cumulativity and ganging in the tonology of Awa suffixes. MS., Dartmouth College.

Monier-Williams, Monier. 1899. A Sanskrit-English dictionary. Oxford: Clarendon Press.

Mullin, Kevin. 2011. Strength in harmony systems: Triggers and directional asymmetries. MS., University of Massachusetts, Amherst. Available on Rutgers Optimality Archive, ROA-1134, http://roa.rutgers.edu.

Myers, Scott. 1997. OCP effects in Optimality Theory. Natural Language and Linguistic Theory 15.847-892.

Ní Chiosáin, Máire, and Jaye Padgett. 1997. Markedness, segment realization, and locality in spreading. Technical Report LRC-97-01, Linguistics Research Center. University of California, Santa Cruz.

Ní Chiosáin, Máire, and Jaye Padgett. 2001. Markedness, segment realization and locality in spreading. Segmental phonology in Optimality Theory, ed. by Linda Lombardi, 118-156. Cambridge, U.K.: Cambridge University Press.

Ohala, John J., and Manjari Ohala. 1993. The phonetics of nasal phonology: Theorems and data. Nasals, nasalization, and the velum, ed. by Marie K. Huffman and Rena A. Krakow, volume 5 of Phonetics and Phonology. San Diego, CA: Academic Press.

Padgett, Jaye. 1995. Feature classes. University of Massachusetts Occasional Papers in Linguistics 18.385-419.

Pater, Joe. 2009a. Review of Smolensky and Legendre (2006). The harmonic mind. Phonology 26.217-226.

Pater, Joe. 2009b. Weighted constraints in generative linguistics. Cognitive Science 33.999- 
1035.

Pater, Joe. 2012. Serial Harmonic Grammar and Berber syllabification. Prosody matters: essays in honor of Lisa O. Selkirk, ed. by Toni Borowsky, Shigeto Kawahara, Takahito Shinya, and Mariko Sugahara, 43-72. London: Equinox Press.

Pater, Joe, Rajesh Bhatt, and Christopher Potts. 2007. Linguistic optimization. Rutgers Optimality Archive 924.

Potts, Christopher, Joe Pater, Karen Jesney, Rajesh Bhatt, and Michael Becker. 2010. Harmonic grammar with linear programming: From linear systems to linguistic typology. Phonology 27.77-117.

Prince, Alan, and Paul Smolensky. 1993/2004. Optimality Theory: Constraint interaction in Generative Grammar. Malden, MA: Blackwell. Technical Report, Rutgers University and University of Colorado at Boulder, 1993. Revised version Blackwell, 2004.

Renou, Louis. 1952. Grammaire de la langue védique. Paris: IAC.

Renou, Louis. 1961. Grammaire sanscrite. Paris: Librairie d'Amérique et d'Orient AdrienMaisonneuve.

Ringen, Catherine O. 1976. Vacuous application, iterative application, reapplication, and the unordered rule hypothesis. The application and ordering of grammatical rules, ed. by Andreas Koutsoudas, 55-75. The Hague: Mouton.

Rose, Sharon, and Rachel Walker. 2004. A typology of consonant agreement as correspondence. Language 80.475-531.

Rose, Sharon, and Rachel Walker. 2011. Harmony systems. The handbook of phonological theory, 2nd edition, ed. by John Goldsmith, Jason Riggle, and Alan C. L. Yu, 240-290. Oxford: Blackwell Publishing.

Sagey, Elizabeth. 1986. The representation of features and relations in non-linear phonology. Doctoral Dissertation, Massachusetts Institute of Technology.

Schein, Barry, and Donca Steriade. 1986. On geminates. Linguistic Inquiry 17.691-744.

Selkirk, Elisabeth O. 1980. Prosodic domains in phonology: Sanskrit revisited. Juncture, ed. by Mark Aronoff, 107-129. Saratoga, CA: Anma Libri.

Shalev, Michael, Peter Ladefoged, and Peri Bhaskararao. 1993. Phonetics of Toda. UCLA Working Papers in Phonetics 84.89-123.

Shaw, Patricia A. 1991. Consonant harmony systems. The special status of coronals, ed. by Carole Paradis and Jean-François Prunet, 125-157. San Diego, CA: Academic Press.

Simonsen, Hanne G., Inger Moen, and Steve Cowen. 2000. Retroflex consonants in Norwegian: Are they really? Evidence from EMA and EPG. Proceedings of the 5th Seminar on Speech Production 113-116.

Smolensky, Paul. 1995. On the internal structure of the constraint component Con of UG. Handout, University of Arizona, ROA-86.

Smolensky, Paul, and Géraldine Legendre. 2006. The harmonic mind: From neural computation to Optimality-Theoretic grammar. Cambridge, Massachusetts: Massachusetts Institute of Technology Press.

Spajić, Siniša, Peter Ladefoged, and Peri Bhaskararao. 1996. The trills of Toda. Journal of 
the International Phonetic Association 26.1-21.

Steriade, Donca. 1986. A note on coronal. MS., Massachusetts Institute of Technology.

Steriade, Donca. 1995. Positional neutralization. MS., University of California, Los Angeles.

Steriade, Donca. 2000. Paradigm uniformity and the phonetics-phonology boundary. Papers in laboratory phonology $V$ : acquisition and the lexicon, ed. by M. B. Broe and J. B. Pierrehumbert, 313-334. Cambridge, U.K.: Cambridge University Press.

Steriade, Donca. 2009. The phonology of perceptibility effects: The P-map and its consequences for constraint organization. The nature of the word: essays in honor of Paul Kiparsky, ed. by Kristin Hanson and Sharon Inkelas. Cambridge, MA: MIT Press.

Ussishkin, Adam. 1999. The inadequacy of the consonantal root: Modern Hebrew denominal verbs and output-output correspondence. Phonology 16.401-442.

Vasu, Srisa Chandra. 1898. The Ashtádhyáyí of Pánini, translated into English by Śríśa Chandra Vasu, volume 8. Allahabad: Indian Press.

Vergnaud, Jean-Roger, and Morris Halle. 1978. Metrical structures in phonology. MS., Massachusetts Institute of Technology.

Wackernagel, Jakob. 1896. Altindische Grammatik, volume 1. Göttingen: Vandenhoeck \& Ruprecht.

Walker, Rachel. 2005. Weak triggers in vowel harmony. Natural Language and Linguistic Theory 23.917-989.

Walker, Rachel. 2014. Nonlocal trigger-target relations. Linguistic Inquiry 45.501-523.

Walker, Rachel, Dani Byrd, and Fidèle Mpiranya. 2008. An articulatory view of Kinyarwanda coronal harmony. Phonology 25.499-535.

Walker, Rachel, and Fidèle Mpiranya. 2005. On triggers and opacity in coronal harmony. Proceedings of BLS, ed. by Rebecca T. Cover and Yuni Kim, volume 31, 383-394. Berkeley, CA.

Whitney, William Dwight. 1889. Sanskrit grammar, including both the Classical language and the older dialects, of Veda and Brahmana. Cambridge, Massachusetts: Harvard University Press, 2nd edition.

Wilson, Colin. 2003. Analyzing unbounded spreading with constraints: Marks, targets, and derivations. MS., University of California, Los Angeles.

Yip, Moira. 2002. Tone. Cambridge, U.K.: Cambridge University Press.

Zuraw, Kie. 2007. The role of phonetic knowledge in phonological patterning: Corpus and survey evidence from Tagalog. Language 83.277-316.

Zuraw, Kie. 2013. *MAP constraints. MS., UCLA. 